\title{
Local flexibility markets: Literature review on concepts, models and clearing methods
}

\author{
Jin, Xiaolong; Jia, Hongjie
}

Published in:

Applied Energy

Link to article, DOI:

10.1016/j.apenergy.2019.114387

Publication date:

2019

Document Version

Peer reviewed version

Link back to DTU Orbit

Citation (APA):

Jin, X., \& Jia, H. (2019). Local flexibility markets: Literature review on concepts, models and clearing methods. Applied Energy, 261, [114387]. https://doi.org/10.1016/j.apenergy.2019.114387

\section{General rights}

Copyright and moral rights for the publications made accessible in the public portal are retained by the authors and/or other copyright owners and it is a condition of accessing publications that users recognise and abide by the legal requirements associated with these rights.

- Users may download and print one copy of any publication from the public portal for the purpose of private study or research.

- You may not further distribute the material or use it for any profit-making activity or commercial gain

- You may freely distribute the URL identifying the publication in the public portal

If you believe that this document breaches copyright please contact us providing details, and we will remove access to the work immediately and investigate your claim. 


\title{
Local flexibility markets: Literature review on concepts, models and clearing methods
}

\author{
Xiaolong Jin ${ }^{\text {a }}$ Qiuwei Wu ${ }^{\text {a,* }}$, Hongjie Jia ${ }^{\text {b }}$ \\ ${ }^{a}$ Center for Electric Power and Energy (CEE), Department of Electrical Engineering, Technical \\ University of Denmark (DTU), 2800 Kgs. Lyngby, Denmark \\ ${ }^{b}$ Key Laboratory of Smart Grid of Ministry of Education, Tianjin University, Tianjin 30072, China
}

Email address: xiajin@elektro.dtu.dk, qw@elektro.dtu.dk, hjjia@tju.edu.cn *Corresponding author: Qiuwei Wu, E-mail address: qw@elektro.dtu.dk 


\begin{abstract}
With high penetration of renewable generation and distributed energy resources (DERs), distribution systems are facing new operational challenges due to their intermittency and uncertainty. To cope with these challenges, distribution system operators (DSOs) are seeking for market tools to enable more active system management and control using flexibility. Local flexibility markets (LFMs) provide opportunities to trade flexibility among DSOs and other participants (e.g., aggregators) in an economically efficient way. Studies have been carried out to define the concepts, design the mechanisms and formulate the market clearing methods of LFMs in the literature. Therefore, there is a need to classify and organize the literature on potential designs and market clearing methods of LFMs. This paper reviews LFMs, which are currently being discussed and designed to provide trading platforms for local participants, including DSOs and aggregators. Starting with a survey on the concepts and definitions of LFMs, we summarize the key elements, technologies and participants of LFMs. Afterwards the formulations of LFMs and the solution methods for LFM clearing are reviewed, based on which future research directions and challenges are suggested in the last section of this paper.
\end{abstract}

Keywords: Aggregator, distribution system operator (DSO), local flexibility markets (LFMs), market designs, market clearing 


\section{Introduction}

Technologies of demand side management (DSM), renewable generations and information and communication (ICT) are drawing more and more attention due to the growing concerns over the energy depletion and environmental issues all over the world [1]. These new technologies are changing the landscape of electric systems, especially the electric distribution systems, by creating new opportunities and challenges to their generations, demands and the systems themselves.

\subsection{Transformations of modern electric systems}

The transformations mainly lie in the following aspects:

\section{(1) Intermittent and uncontrollable generations}

Generations of electric systems are getting more and more intermittent and uncontrollable due to the increasing penetration of renewable generations with intermittency and uncertainty. Countries around the world are promoting the connection of renewable generations through many realistic support policies and mechanisms [2]. As pointed out in [3], renewable generations' share of the worldwide electricity production is around $25 \%$ due to these support policies and mechanisms. In Europe, these support policies and mechanisms are motivated by a series of regulatory targets, e.g., $20 \%$ of EU energy from renewable generations by 2020 in '2020 climate \& energy package' [4] and at least $32 \%$ share for renewable generations by 2030 in '2030 climate \& energy framework' [5]. Denmark plans to satisfy $100 \%$ of Denmark's energy demand with renewable generations by 2050 [6]. Following this target, oil for heating purposes and coal are to be phased out by 2030 [6]. Germany also decides its goal to cover $80 \%$ of the electricity demand with renewable generations by 2050 [7].

\section{(2) Controllable and flexible consumers}

The recent years experienced a fast increase of distributed energy resources (DERs), which are normally connected to residential houses, smart buildings, microgrids and distribution systems [8]. DERs mainly include distributed generators (DGs), energy storages and controllable loads (e.g., electric vehicles, heat pumps). The DERs can be potential providers of flexibility with the demand response (DR) technologies [9]. With the increasing connections of DERs and the fast developments in ICT at the demand side, traditional consumers are transforming to prosumers [10], who can not only consume energy but also share excessive energy with other prosumers and/or the distribution system operator (DSO). Therefore, the prosumers can participate in energy generation/consumption process and provide flexible services by managing their DERs and communicating with other prosumers and the DSO [11]. 
In other words, the prosumers can trade energy and flexibility among themselves and the DSO locally based on the information exchange and local market platforms [12].

Take a smart building as an example, as a prosumer with ICT infrastructure, the smart building can manage its resources in an economically efficient way (as shown in Fig. 1), and trade energy and flexibility with other smart buildings or DSO locally [13], [14] (as shown in Fig. 2). As pointed out by the International Energy Agency, buildings' energy consumption occupies around 40\% of the worldwide energy usage, and their heating, ventilation and air conditioning (HVAC) systems are responsible for almost half of the buildings' energy consumption [15]. With the rapid progress of urbanization and the transformation of industrial structure around the world, this proportion will be increasing continually [14]. Therefore, buildings are potential prosumers who can provide flexibility locally [14].

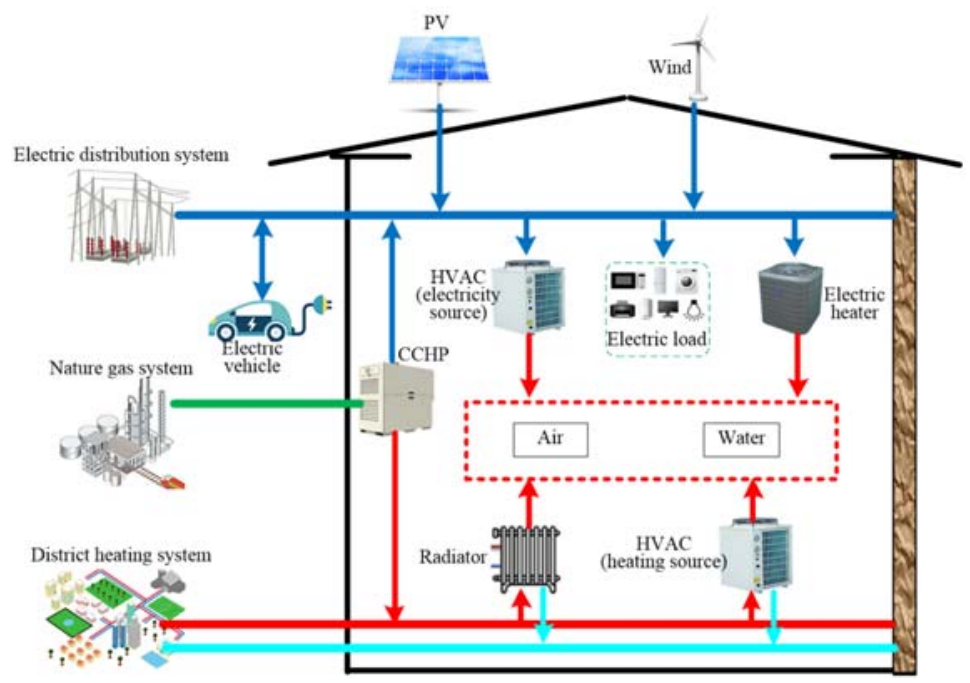

Fig. 1. Schematic diagram of a smart building with connection of DERs.

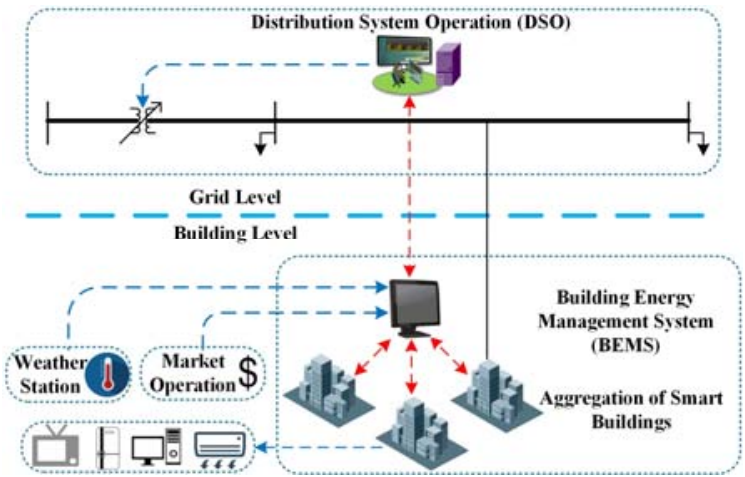

Fig. 2. Schematic diagram of energy trading among the smart buildings and the DSO (adopted from [14]).

\section{(3) Intelligent and smart systems}

The fast development of sustainable energy productions and utilizations requires more intelligent systems with real-time control capabilities as well as bidirectional communications with prosumers [16]. 
With recent advances in ICT and the wildly applied electronics devices, electric systems have experienced a strong evolution recently [17]. In this context, the traditional electric systems are transforming to more intelligent and smart systems, which are the so-called smart grids. The transition from traditional systems to smart systems is witnessed worldwide, with demonstrations in Europe [18], United States [19], China [19] and Australia [20].

The schematic diagram of a smart distribution system with ICT infrastructure is shown in Fig. 3 [16]. The ICT infrastructure enables the smart distribution system monitor, control and manage the whole system and all the interconnected components, which benefits itself mainly in [21]: 1) reliability and resilience improvements due to automated self-healing technologies; 2) increased revenue and decreased operational cost; 3) carbon footprint reduction due to optimal operation and planning approaches; 4) increase in penetration of renewable generations and DERs due to intelligent control approaches; 5) flexible integration with DR activities [22].

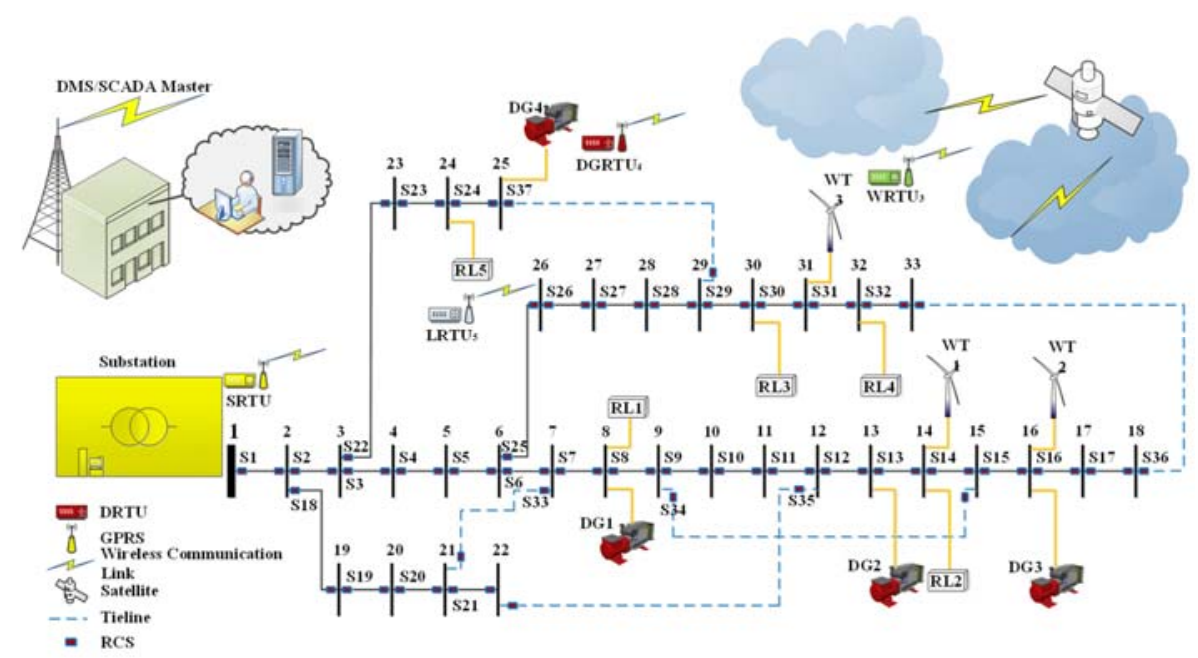

Fig. 3. Schematic diagram of a smart distribution grid with ICT (adopted from [16]).

\section{(4) Bi-directional and decentralized systems}

The traditional distribution systems are transforming from unidirectional centralized systems to bidirectional decentralized systems due to the increasing penetration of DERs [23]. As shown in Fig. 4, compared to a highly centralized Danish power infrastructure in 1985, the power infrastructure in 2018 has been changed to a decentralized system with high penetrations of decentralized wind generations and CHP plants [24]. This transition leads to several operational challenges on distribution systems, such as voltage violations, overloading problems, high line losses, and other aspects of power quality [25]. Their safe and secure operations would be challenging. 


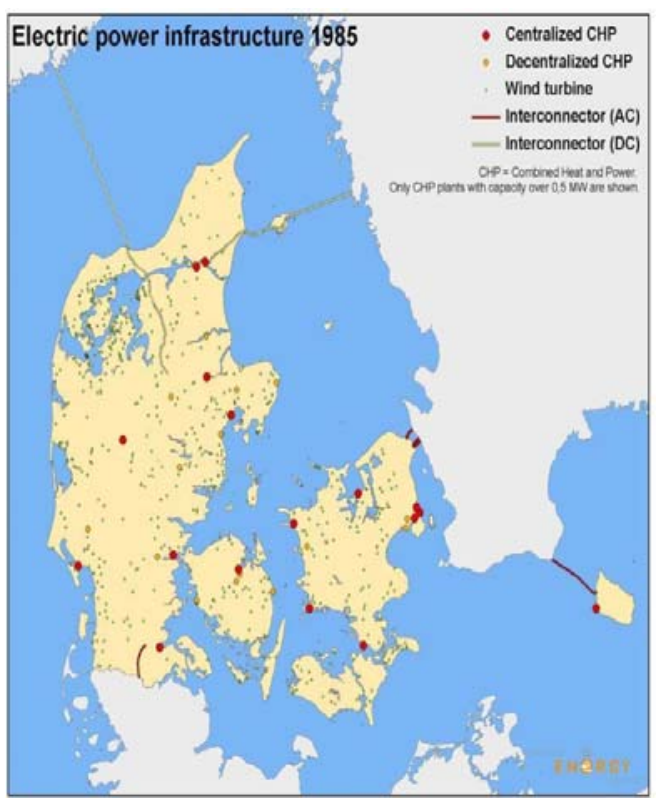

(a) 1985

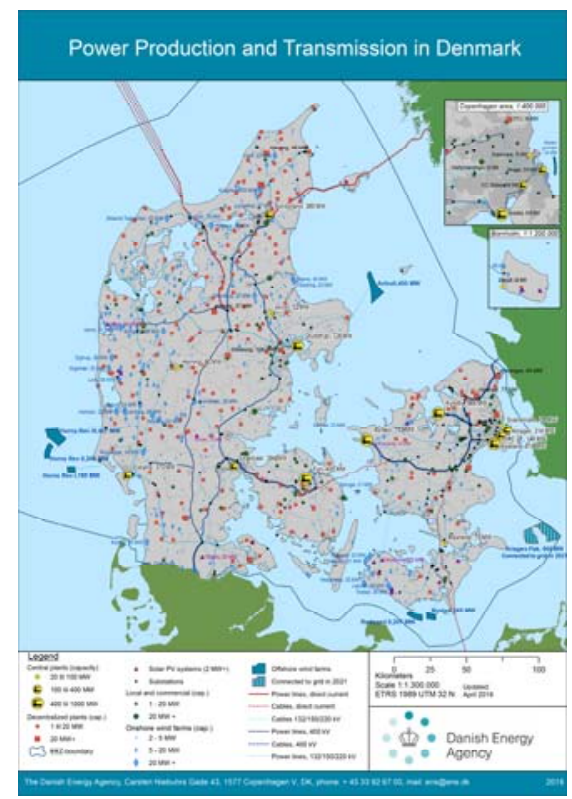

(b) 2018

Fig. 4. Evolution of the Danish power system (from 1985 to 2018).

\section{(5) Multi-energy systems}

Traditionally different energy systems, e.g., gas networks, electricity networks and heating networks, are planned and operated independently. Actually, these energy systems are tightly coupled via different coupling technologies and devices, including combined cycle gas turbines (CCGT), combined heat and power units (CHPs), power to gas ( $\mathrm{P} 2 \mathrm{G})$ equipment ${ }^{1}$, heat pumps and heating, ventilation and airconditioning systems (HVACs) [26]. Consequently, it leads to the multi-energy systems. Fig. 5 shows the schematic diagram of the multi-energy systems with interactions among different energy networks at various scales, i.e., from transmission, distribution scale down to building level [26]. The electric systems can get cost effective provision of flexibility by capitalizing on synergies and complementary advantages of the various energy systems. Several benefits can be achieved by using the flexibility properly, which mainly include facilitating the integration of DERs [27]; reduction of operational cost of different energy systems; delay of capital cost on electric systems [28]; resilience and reliability improvements [29]; and opportunities for innovative business (e.g., transactive energy (TE) [30], smart contracts [31], local energy market (LEM) [12], peer-to-peer (P2P) energy trading [10], etc.).

\footnotetext{
${ }^{1}$ The P2G equipment can use excess renewable generations to produce hydrogen, which can be injected to the gas network or converted to synthetic natural gas (SNG), and then injected into the gas network.
} 


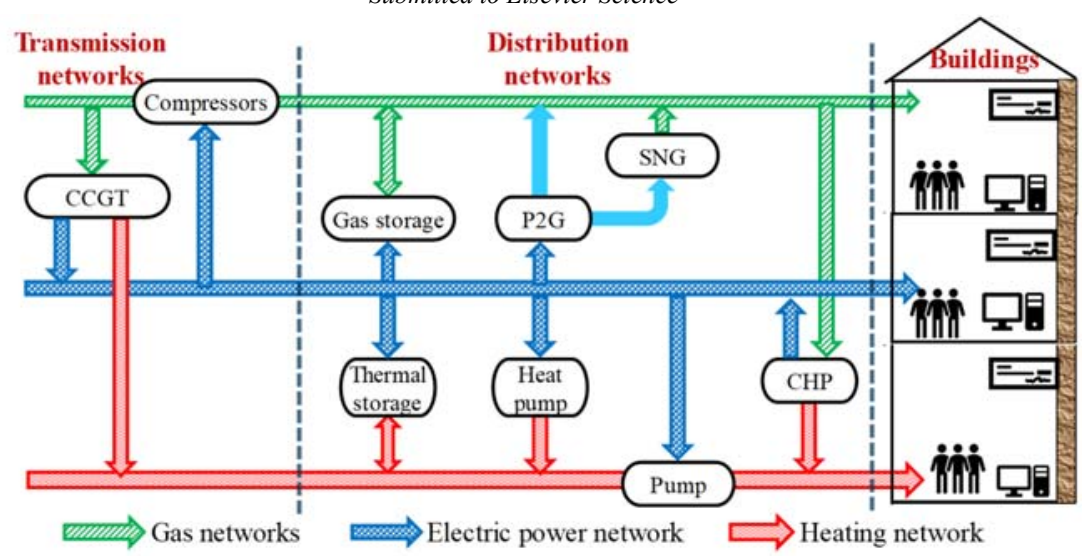

Fig. 5. Schematic diagram of a multi-energy system from transmission, distribution scale down to building level (adopted from [26]).

\subsection{Drivers for flexibility}

The transformations of the electric systems introduced in Section 1.1 are challenging the operations of electric systems, and providing new opportunities for operating them in a more secure, sustainable and economical way. The motivations for introducing flexibility in the electric systems lie in the following aspects:

(1) The intermittent and uncontrollable generations are challenging the secure operations of electric systems because of the increasing uncertainty at the generation side, which is supposed to be controllable and predictable in traditional electric systems. This means flexibility is highly needed in the electricity sector [32].

(2) The increasing number of DERs connected to the demand side make the electric distribution systems more complex (i.e., the bi-directional and decentralized systems). It causes reverse power flows, voltages violations, congestions and line losses. The safe and secure operation of the distribution systems would be challenging. The flexibility is also highly needed by DSOs to cope with these challenges. This idea of introducing flexibility to solve the operational challenges of distribution systems is also encouraged by policy makers [33].

(3) The flexibility services can be realized by the flexibilization of both the generation and consumption side of the electric systems, and the integration of other energy vectors, as introduced in Section 1.1. The controllable and flexible consumers (i.e., prosumers) with the intelligent and smart systems technologies can trade flexibility among themselves and the DSO locally, which represent significant sources for flexibility. Furthermore, the multi-energy systems offer great opportunities for the electric systems to get cost effective flexibility by capitalizing on synergies and complementary advantages of the various energy systems at various scales, i.e., from transmission, distribution scale down to building level. 
As introduced in Section 1.2, flexibility is highly needed by the transmission system operator (TSO) to balance power and control its frequency, while the DSO needs flexibility for local balancing, voltages or congestion management. Three different types of flexibility products for different purposes are summarized according to the literature, which are the main drivers for flexibility trading and markets.

Type 1: Balancing flexibility for the TSO at the transmission system, which is normally traded in fully developed markets such as intra-day energy markets [35] and spinning reserve markets [36].

Type 2: Balancing flexibility for the TSO at the distribution system, which is provided by the DERs at the distribution system [37]. Markets for this type of flexibility are needed to support the flexibility trading. The TSO-DSO coordination is recommended to avoid potential problems to the distribution system due to the flexibility services to the TSO [34], [38]. Hence, TSO's seeking for flexibility from the distribution systems is one major driver for flexibility trading and its market mechanism.

Type 3: Flexibility for the DSO at the distribution system: which is used for voltage control, congestion management, local balancing and losses reduction. The DSO is also seeking for market tools to enable more active system management and control using this type of flexibility. Local flexibility markets (LFMs) provide opportunities and trading environments for the DSO by encouraging localized flexibility trading. Hence, the DSO's seeking for cost effective flexibility is another major driver for local flexibility trading and LFM. The topic of LFM for trading Type 3 flexibility for the DSO has been discussed in the literature and the industry due to the transformation of distribution systems and their operational challenges [38].

\subsection{Motivations of this review}

The paper focuses on trading Type 3 flexibility and its LFM in distribution systems with high penetration of renewable generations and DERs. The LFM provides DSO with a market-based approach to system management and control using local flexibility. The concepts and definitions of local flexibility trading and LFM have been treated in the literature. Various formulations and market clearing methods have been developed and utilized widely. Therefore, there is a need to classify and organize the literature on potential designs and market clearing methods of the LFM. Fig. 6 summarizes the structure of this paper.
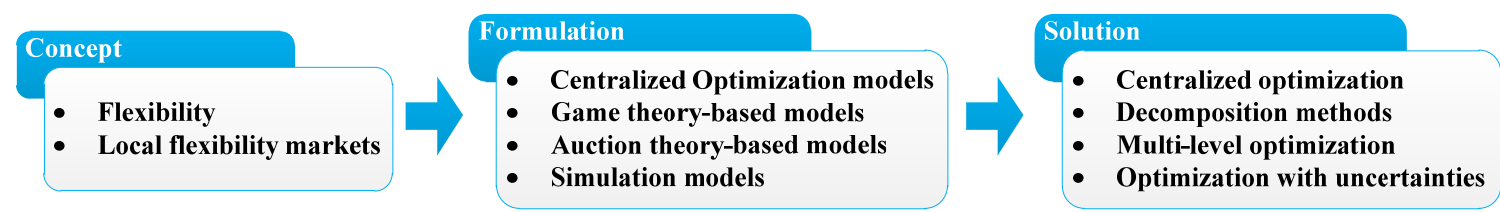

Fig. 6. Structure of this review. 
The structure of this paper is introduced as follows. In Section 2, the concepts and definitions of LFMs are reviewed. Section 3 summarizes and compares studies in the literature for solving operational issues of distribution systems due to high penetration of DERs. Section 4 presents a detailed review on the formulations of LFMs and the designs of LFM. Section 5 classifies and organizes the solution approaches for LFM clearing. The future research directions are suggested in Section 6. Finally, Section 7 concludes the whole paper.

\section{Concepts of local flexibility market}

\subsection{Flexibility}

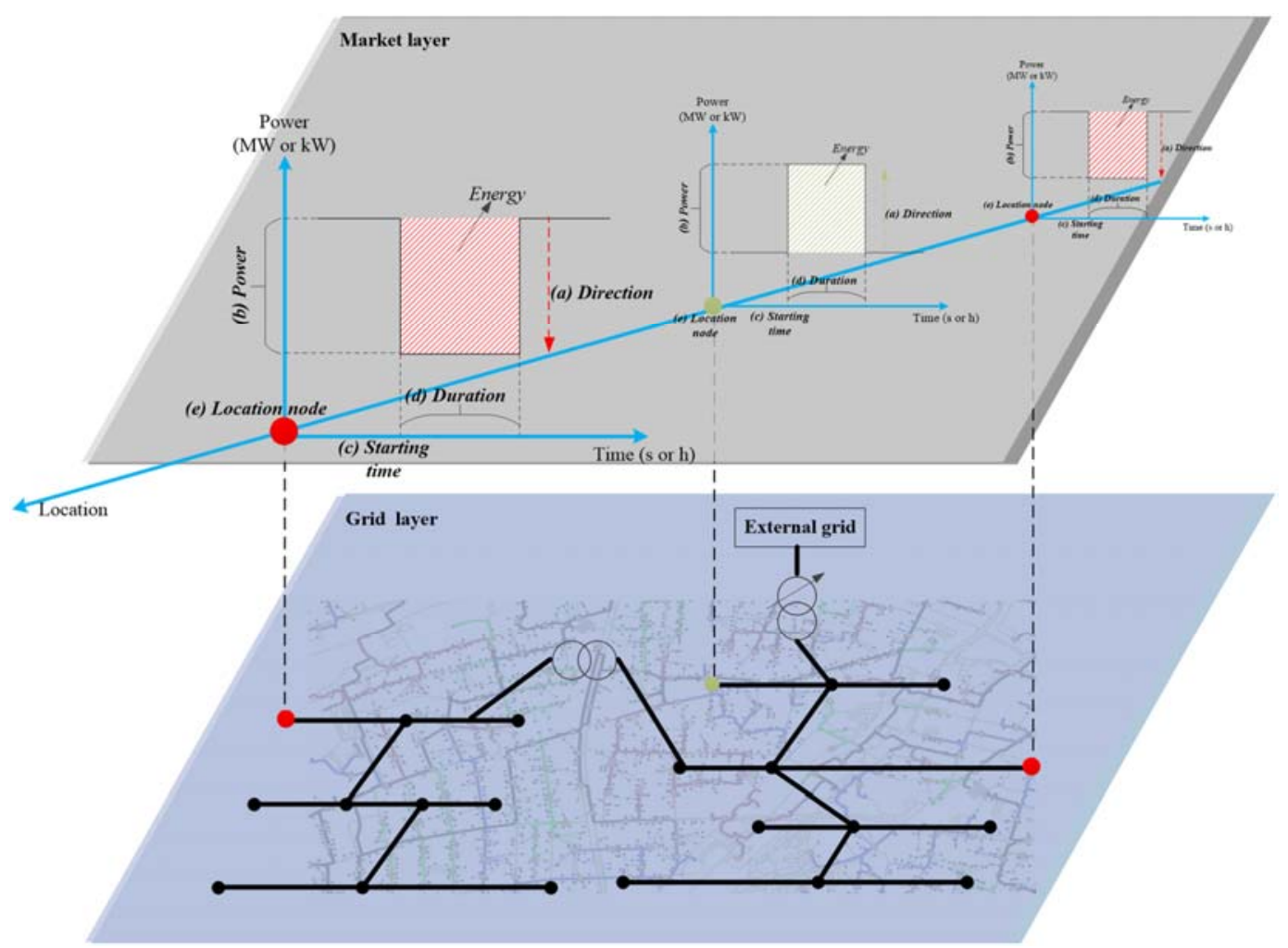

Fig. 7. Five attributes of Type 3 flexibility.

Ref. [39] defines flexibility as the possibility of adjusting patterns of generation and consumption in reaction to a signal (price or activation signals) to contribute to different services. Particularly, the Type 3 flexibility (hereafter abbreviated as flexibility) is considered as the services or commodities to be traded in LFMs in response to the flexibility needs introduced in Section 1.2. Technically, the flexibility can be defined as a power modification activated at a defined time for a defined duration at a specific location node within the distribution system. Thus, it can be described by five attributes [9], [34], as shown in Fig. 7: 
(a) Direction, i.e., up or down.

(b) Rate of change, i.e., power capacity.

(c) Starting time and its trigger.

(d) Duration.

(e) Location, i.e., node of distribution systems.

A R\&D European project named 'ADDRESS' defined three different kinds of flexibility products from demand side, which are summarized in Table 1 [40]. There are already several industrial projects on flexibility utilization for managing the operation of electric power systems carried out worldwide. Some representative projects are summarized in Table 2.

Table 1

Flexibility products from demand side [40]

\begin{tabular}{|c|c|c|c|c|}
\hline Flexibility product & \multicolumn{2}{|c|}{ Conditionality } & \multicolumn{2}{|l|}{ Typical example } \\
\hline $\begin{array}{l}\text { Scheduled reprofiling } \\
\text { (SRP) }\end{array}$ & \multicolumn{2}{|c|}{$\begin{array}{l}\text { Unconditional } \\
\text { (obligation) }\end{array}$} & \multicolumn{2}{|c|}{$\begin{array}{c}\text { The aggregator has the duty to provide a specified power adjustment at a } \\
\text { defined time for a defined duration. }\end{array}$} \\
\hline $\begin{array}{l}\text { Conditional reprofiling } \\
\text { (CRP) }\end{array}$ & \multicolumn{2}{|c|}{$\begin{array}{l}\text { Conditional (real } \\
\quad \text { option) }\end{array}$} & \multicolumn{2}{|c|}{$\begin{array}{l}\text { The aggregator must have the capacity to provide a specified power } \\
\text { adjustment during a defined duration. The delivery is called upon by the } \\
\text { buyer of the flexibility. }\end{array}$} \\
\hline $\begin{array}{l}\text { Bi-directional } \\
\text { conditional reprofiling } \\
(\mathrm{CRP}-2)\end{array}$ & \multicolumn{2}{|c|}{$\begin{array}{l}\text { Conditional (real } \\
\text { option) }\end{array}$} & \multicolumn{2}{|c|}{$\begin{array}{l}\text { The aggregator must have the capacity to provide a specified power } \\
\text { adjustment during a defined duration in a bi-directional range }[-y, x] \\
\text { MW. The delivery is called upon by the buyer of the flexibility. }\end{array}$} \\
\hline & & & Table 2 & \\
\hline \multicolumn{5}{|c|}{ Flexibility related industrial projects } \\
\hline Project name & $\begin{array}{l}\text { Start } \\
\text { year }\end{array}$ & Country & Purpose & $\begin{array}{l}\text { System } \\
\text { size }\end{array}$ \\
\hline iPower project [41] & 2011 & Denmark & $\begin{array}{l}\text { Introduce a 'clearinghouse' for local flexibility trading at } \\
\text { the DSO level to solve congestions in local distribution } \\
\text { systems }\end{array}$ & Regional \\
\hline PeerEnergyCloud [42] & 2012 & Germany & $\begin{array}{l}\text { Construct a virtual market platform to trade electricity in a } \\
\text { microgrid }\end{array}$ & Microgrid \\
\hline ECO-Grid project [43] & 2013 & Denmark & $\begin{array}{l}\text { Use market mechanisms and smart control of electricity } \\
\text { consumption to involve private customers in balancing an } \\
\text { energy system with rich renewables }\end{array}$ & Regional \\
\hline Piclo [44] & 2014 & UK & Provide customers with data visualizations and analytics & National \\
\hline $\begin{array}{l}\text { Horizon 2020-project } \\
\text { EMPOWER [45] }\end{array}$ & 2015 & Europe & $\begin{array}{l}\text { Elaborate a local market concept with three basic types of } \\
\text { market platforms for local electricity trading, local } \\
\text { flexibility trading and other services }\end{array}$ & Regional \\
\hline
\end{tabular}

\subsection{Sources of flexibility}

A schematic summary of the electric distribution system with flexibility sources are shown in Fig. 8. Flexible sources of an electric distribution system mainly consist of supply-side flexibility, demand-side flexibility and grid-side flexibility [46]: 


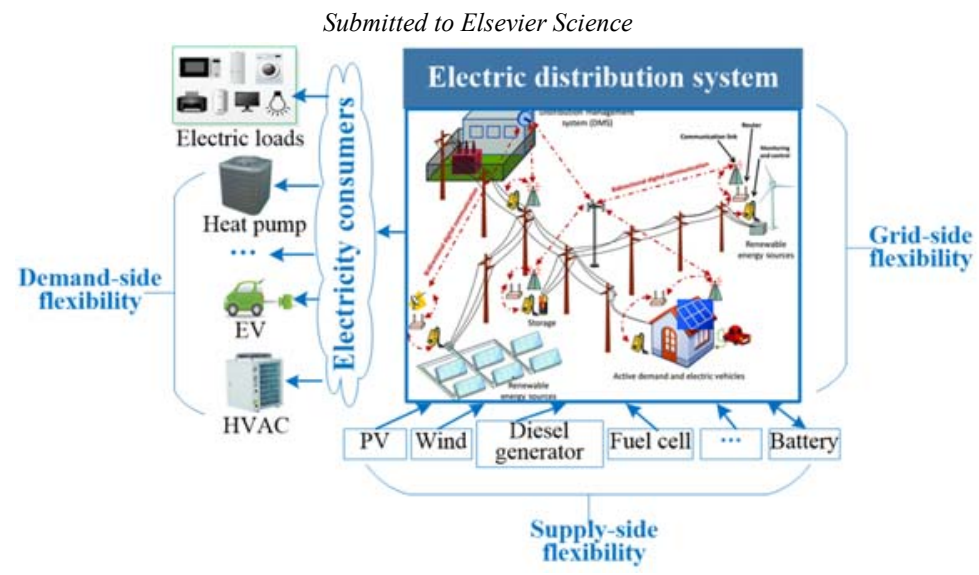

Fig. 8. Sources of flexibility in an electric distribution system.

(1) Supply-side flexibility is realized by the coordinated operation of multiple DGs (e.g., CHP, diesel generator, fuel cell, etc.) and energy storage units. The literature has demonstrated that optimized operation of DGs and storages can generate enormous supply-side flexibility [11], [13], [16], [27], [47][51], which benefits the operation of the distribution system and even the transmission system through the TSO-DSO coordination [37], [52]-[54].

(2) Demand-side flexibility is normally realized through the DSM [55], which provides opportunities to change the patterns of energy consumption of a prosumer or an aggregator of multiple prosumers [56]. The prosumer can be a smart home, a smart building or a microgrid with flexible demands. HVAC systems have been demonstrated to have enormous potential in DSM [14], in which the demand-side flexibility can be utilized efficiently to help the operation of the distribution system. A control strategy for aggregated buildings was proposed in [57] for the power system frequency control under both normal and emergency conditions. A hierarchical control method for aggregated HVACs was proposed in [58] to provide primary frequency support. Two methods were presented in [59] to use aggregated HVACs for resolve congestion for a distribution system. Furthermore, a building can be modelled as a virtual energy storage system (VESS) [13]-[14], [60]-[61], which can provide demand-side flexibility by using the building's heat inertia due to its thermal mass. As a flexible resource, electric vehicles (EVs) can shift their charging loads during peak hours and provide demand-side flexibility [62]-[63]. Industrial DR is also a mature technology [64]. Industrial consumers can provide their DR services through balancing markets and a lot of papers has assessed the benefits [65]-[67].

(3) Grid-side flexibility can be achieved by control the grid and grid equipment (e.g., on-load tap changer (OLTC) [68], capacitor banks [69], parallel transformers [70], soft open point (SOP) [71], etc.). Network reconfiguration optimizes the network topology of the distribution systems by changing the open/ close status of the switches. It is a commonly used control method for the distribution system. It is shown in [16] and [27] that the network reconfiguration can increase the power supply capability of the 
distribution system. The increased power supply capacity is contributed as the grid-side flexibility of the distribution system. Furthermore, improved reactive power distribution [68], improved voltage quality [69], optimized and controllable power flow [71] can be realized by controlling the grid equipment. These improvements further provide grid-side flexibility for the distribution system. The parallel transformers owned by the distribution systems were controlled in [70] to provide voltage support for the transmission networks by generating reactive power. Sources of flexibility coming from different ways in a distribution system are summarized in Table 3.

Table 3

Classification of sources of flexibility

\begin{tabular}{|c|c|c|c|c|c|}
\hline Ref. & Sources of flexibility & $\begin{array}{l}\text { Supply- } \\
\text { side } \\
\text { flexibility }\end{array}$ & $\begin{array}{l}\text { Demand- } \\
\text { side } \\
\text { flexibility }\end{array}$ & $\begin{array}{l}\text { Grid-side } \\
\text { flexibility }\end{array}$ & Flexibility services \\
\hline$[10]$ & Water heater & $\times$ & $\sqrt{ }$ & $x$ & $\begin{array}{l}\text { Trade energy and balance power in a } \\
\text { microgrid }\end{array}$ \\
\hline$[11]$ & Battery & $\sqrt{ }$ & $x$ & $x$ & $\begin{array}{c}\text { Facilitate PV generation and balance } \\
\text { power in a microgrid }\end{array}$ \\
\hline $\begin{array}{c}{[13],[60],} \\
{[61]}\end{array}$ & $\begin{array}{l}\text { DGs (i.e., diesel } \\
\text { generator, fuel cell), } \\
\text { battery, electric } \\
\text { chiller, VESS }\end{array}$ & $\sqrt{ }$ & $\sqrt{ }$ & $x$ & $\begin{array}{l}\text { Reduce the operating cost of a } \\
\text { microgrid }\end{array}$ \\
\hline$[14]$ & HVAC, OLTC & $x$ & $\sqrt{ }$ & $\sqrt{ }$ & $\begin{array}{l}\text { Reduce the operating cost of a } \\
\text { buildings aggregation, and reduce the } \\
\text { power loss and improve the voltage } \\
\text { quality of a distribution system }\end{array}$ \\
\hline$[16]$ & $\begin{array}{l}\text { DGs, flexible loads, } \\
\text { network } \\
\text { reconfiguration }\end{array}$ & $\sqrt{ }$ & $\sqrt{ }$ & $\sqrt{ }$ & $\begin{array}{l}\text { Reduce the operating cost of a } \\
\text { distribution system }\end{array}$ \\
\hline$[21]$ & $\begin{array}{l}\text { DGs, battery, flexible } \\
\text { loads }\end{array}$ & $\sqrt{ }$ & $\sqrt{ }$ & $x$ & $\begin{array}{l}\text { Trade flexibility in a LFM that } \\
\text { enables satisfaction of DSO's request } \\
\text { on flexibility }\end{array}$ \\
\hline$[22],[46]$ & $\begin{array}{l}\text { Office building, water } \\
\text { heater, hot water } \\
\text { storage }\end{array}$ & $\sqrt{ }$ & $\sqrt{ }$ & $x$ & $\begin{array}{c}\text { Reduce the operational cost of a } \\
\text { building }\end{array}$ \\
\hline $\begin{array}{c}{[25],[30]} \\
{[62]}\end{array}$ & EVs & $x$ & $\sqrt{ }$ & $x$ & $\begin{array}{l}\text { Help the DSO for congestion } \\
\text { management }\end{array}$ \\
\hline$[27],[28]$ & $\begin{array}{l}\text { DGs (i.e., CHP, gas } \\
\text { boiler), flexible loads, } \\
\text { network } \\
\text { reconfiguration, } \\
\text { HVAC }\end{array}$ & $\sqrt{ }$ & $\sqrt{ }$ & $\sqrt{ }$ & $\begin{array}{l}\text { Reduce the operational cost of } \\
\text { integrated energy systems }\end{array}$ \\
\hline$[33]$ & $\begin{array}{l}\text { Industrial aggregator, } \\
\text { residential aggregator }\end{array}$ & $x$ & $\sqrt{ }$ & $x$ & $\begin{array}{l}\text { Trade flexibility in a LFM that } \\
\text { enables satisfaction of DSO's request } \\
\text { on flexibility }\end{array}$ \\
\hline$[37]$ & $\begin{array}{l}\text { DGs, microgrids, } \\
\text { EVs, network } \\
\text { reconfiguration }\end{array}$ & $\sqrt{ }$ & $\sqrt{ }$ & $\sqrt{ }$ & $\begin{array}{l}\text { Use flexibility to help the } \\
\text { transmission system on overload } \\
\text { relief through the TSO-DSO } \\
\text { coordination }\end{array}$ \\
\hline [49] & Battery & $\sqrt{ }$ & $x$ & $x$ & $\begin{array}{c}\text { Voltage control for a distribution } \\
\text { system }\end{array}$ \\
\hline$[64]$ & Prosumer aggregators & $x$ & $\sqrt{ }$ & $x$ & $\begin{array}{c}\text { Help the DSO for congestion } \\
\text { management }\end{array}$ \\
\hline$[68],[69]$ & $\begin{array}{l}\text { OLTC, capacitor } \\
\text { banks }\end{array}$ & $\times$ & $x$ & $\sqrt{ }$ & $\begin{array}{l}\text { Control the voltage and facilitate PV } \\
\text { for a distribution system }\end{array}$ \\
\hline
\end{tabular}


SOP, network reconfiguration
Prosumer aggregators

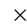

Not mentioned

\section{$\sqrt{ }$}

$\sqrt{ }$

\section{3. $L F M S$}

\subsubsection{Concepts of LFMs}

A market is a place where several parties can gather to facilitate the exchange of goods or services [1]. The parties involved are usually buyers, sellers and retailers in the market [12]. Likewise, a local market is defined as a unique spatial place that serves a specific business purpose [72]. By analogy with the definitions of a market and a local market, a LFM can be defined as an electricity ${ }^{2}$ flexibility trading platform to trade flexibility in geographically limited areas such as neighbor-hoods, community, towns, and small cities [21]. Therefore, a LFM includes commodity or service (i.e., flexibility introduced in Section 2.2) to be traded in the LFM, market operator, market participants, and market clearing mechanism. This is also how this review organized.

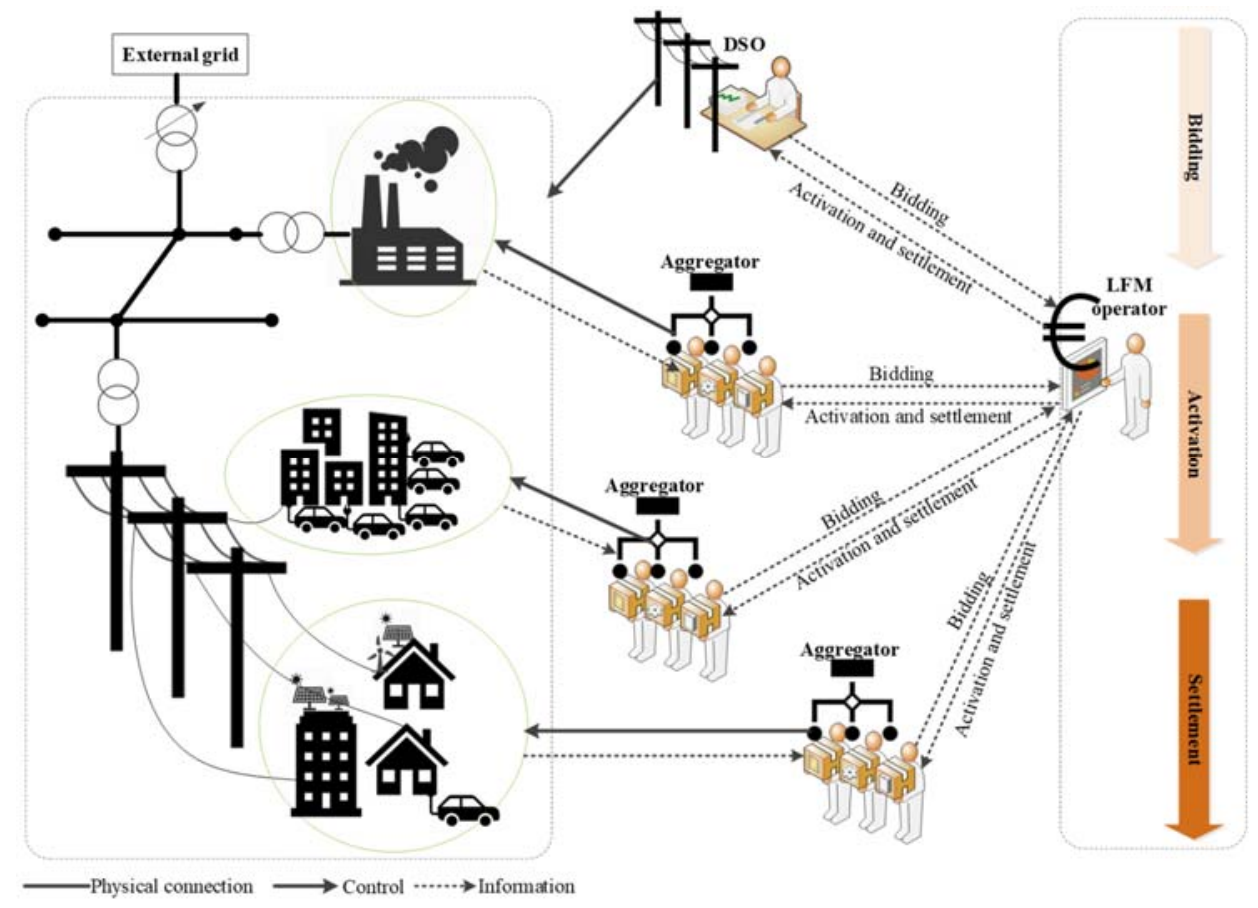

Fig. 9. Schematic overview of a LFM.

${ }^{2}$ Platforms trading other energy like gas, heating are out of scope of this paper. 
Fig. 9 presents a LFM where the DSO and several aggregators are trading flexibility locally under the supervision of a LFM operator. Residential prosumers and industrial prosumers (e.g., industrial loads with flexibility [74]) are managed by the aggregators to participate in the LFM. The LFM shown in Fig. 9 provides a competitive trading platform which is utilized to trade flexibility as commodity between flexibility buyers (e.g., the DSO) and flexibility sellers (e.g., the aggregators). The DSO buy flexibility for load balancing, voltage control and congestion management, loss reduction and other system operation purposes. The aggregators sell the flexibility for profits by modifying their electricity usage upon request and earn profits based on flexibility transactions.

The time sequence of the local flexibility trading in the LFM is also shown in Fig. 9. Bidding is the first process of local flexibility trading when the DSO posts the flexibility requirement at the LFM with a deadline for the aggregators to bid their flexibility offers. During the bidding process, the DSO and the aggregators communicate with each other to reach the agreement on the trading price and quantity of flexibility. During the flexibility activation process, the DSO activates the flexibility request. The aggregators schedule and control their prosumers to provide the activated flexibility. The last process is settlement. In this process, the flexibility transactions are completed through settlement arrangements and payment. An aggregator may be unable to provide the exact quantity of flexibility as it promised due to uncertainties. The mismatch between the promised and actual flexibility quantity must be balanced in the last process [10]. It is worth noting that other participants, e.g., the balance responsible parties (BRPs), can also participate in the LFM.

\subsubsection{Key elements and technologies of LFMs}

A four-layer structure is demonstrated to clarify and classify the potential key elements and technologies used in LFMs, as shown in Fig. 10. Each layer of the four-layer structure is introduced as follows:

(1) The power grid layer is composed of all the physical components of the electric distribution system, including components providing supply-side flexibility (e.g., various DGs, energy storage units, etc.), components providing demand-side flexibility (e.g., prosumers, aggregators, etc.) and components providing grid-side flexibility (e.g., feeders, OLTCs, transformers, SOP, smart meters, etc.). These components compose the electric distribution system where local flexibility trading is conducted.

(2) The ICT layer is composed of communication devices, protocols, applications and information flow to support local flexibility trading [10]. The ICT layer enables the distribution system monitor, control and manage the system and all the components. It also provides ICT infrastructure for local flexibility trading. 


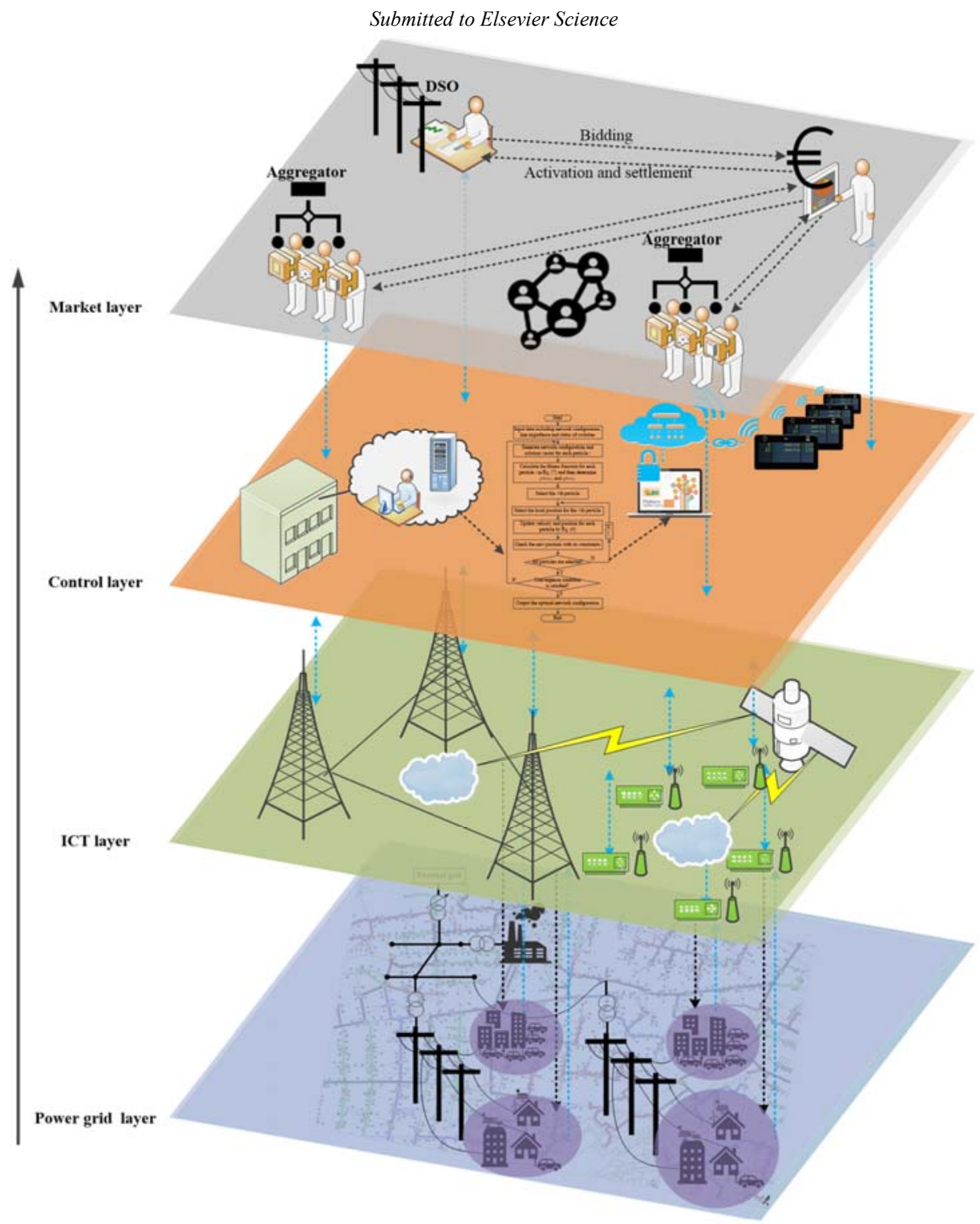

Fig. 10. A four-layer architecture of local flexibility trading.

(3) The control layer is mainly composed of the control functions for the supply-side, the demandside and the grid-side of the distribution system. Supply-side control strategies are facilitated in this layer to control and optimize the operation of various DGs and energy storage units for providing supply-side flexibility. Demand-side strategies are defined in this layer to control and manage the demand-side resources for providing demand-side flexibility. Grid-side strategies are defined in this layer to control the power flow, the voltage and the network topology for preserving the quality and reliability of the distribution system. It further contributes to grid-side flexibility. Different control-based methods including active network management (ANM), price-based control and TE are also implemented in this 
layer. The control layer is also responsible for the management of the flexibility orders decided in the market layer.

(4) The market layer determines how flexibility is traded locally among the participants in the LFM. The participants mainly include DSO, aggregator, BRP and LFM operator. The details of the participants in the LFM is introduced in Section 2.3.3. The market layer is responsible for the management of flexibility transactions in the LFM. Various business models can be integrated in this layer to facilitate different kinds of local flexibility trading.

\subsubsection{Participants in LFMs}

The participants and their objectives in LFMs should be defined firstly before the design of the markets for trading flexibility locally. Then, different approaches can be used with the defined objectives of the participants for market clearing, which is introduced in Section 4. Generally, key participants in LFMs are:

(1) DSO: The DSO is the operator of the distribution system, whose main task is to deliver electricity to customers in a cost-effective, sustainable and efficient way. The DSO is responsible for the secure operation of the distribution system and the quality of electricity delivery services [72]. The DSO can procure flexibility for different operational purposes (e.g., load balancing, congestion management, voltage control, loss minimization, etc.) and planning purposes (e.g., deferring the need for network reinforcements).

(2) BRP: BRPs are defined as traders on energy markets on behalf of members of their portfolio [75]. BRPs are responsible to balance energy supply and energy consumption during a given time duration. If the BRP failed to maintain the balance, it would be charged for imbalance costs. Therefore, BRPs could procure flexibility to optimize their portfolio and realize their energy obligations.

(3) Aggregator: The aggregator is defined as "a company who acts as an intermediary between electricity end-users and DER owners and the power system participants who wish to serve these endusers or exploit the services provided by these DERs" [76]. The individual DER or prosumer has limited negotiating power in LFMs due to their limited volumes of flexibility. In order to exploit the flexibility potential of individual DERs and prosumers, the aggregators harvest the individual flexibility to form various kinds of flexibility services and trade the flexibility in LFMs. The aggregators represent DERs and prosumers to trade in LFMs and get paid by the DSO and BRPs for delivering flexibility services.

(4) LFM operator: LFM operator runs the LFM as an independent entity. A LFM operator provides a flexibility trading platform and is also responsible for market clearing as well. Market clearing is the process that collects flexibility offers and flexibility requests, and determines trading results (i.e., price and quantity of flexibility to be traded). Various roles can be assigned to the LFM operator. In [33] and 
[77], the DSO has the LFM operator role in the LFM simultaneously. In [73], the aggregator is also the LFM operator in the LFM simultaneously. Participants in LFMs and their relevant references are summarized in Table 4.

Table 4

Classification of participants in LFMs (the merged cells mean that the participants are merged as one in the LFM)

\begin{tabular}{|c|c|c|c|c|}
\hline Ref. & DSO & $\begin{array}{c}\text { LFM } \\
\text { operator }\end{array}$ & Aggregator & BRP \\
\hline [21] & $\sqrt{ }$ & $\sqrt{ }$ & $\sqrt{ }$ & $x$ \\
\hline [33] & & & $\sqrt{ }$ & $x$ \\
\hline [64] & $\sqrt{ }$ & $\sqrt{ }$ & $\sqrt{ }$ & $x$ \\
\hline [72] & $\sqrt{ }$ & $\sqrt{ }$ & $\sqrt{ }$ & $\sqrt{ }$ \\
\hline [73] & $\sqrt{ }$ & & & $\sqrt{ }$ \\
\hline [77] & & & $\sqrt{ }$ & $\times$ \\
\hline [78] & $\sqrt{ }$ & $\sqrt{ }$ & $\sqrt{ }$ & $\sqrt{ }$ \\
\hline [79] & $\sqrt{ }$ & $\sqrt{ }$ & $\sqrt{ }$ & $\times$ \\
\hline$[80]$ & $\sqrt{ }$ & $\sqrt{ }$ & $\sqrt{ }$ & $x$ \\
\hline [81] & $\sqrt{ }$ & $\sqrt{ }$ & $\sqrt{ }$ & $x$ \\
\hline
\end{tabular}

TSOs can be potential participants in LFMs through the TSO-DSO coordination [82]. And several benefits can be achieved by sharing flexible reserves between DSOs and TSOs through the TSO-DSO coordination, as introduced in [37].

\section{Methods for solving operational problems for distribution systems}

As introduced in Section 2.3.3, the DSO can procure flexibility in a LFM for solving its operational issues due to high penetration of DERs. In addition to LFMs, other methods for similar purposes are also widely discussed in the literature. Therefore, this section summarizes and compares these methods for solving operational problems for distribution systems.

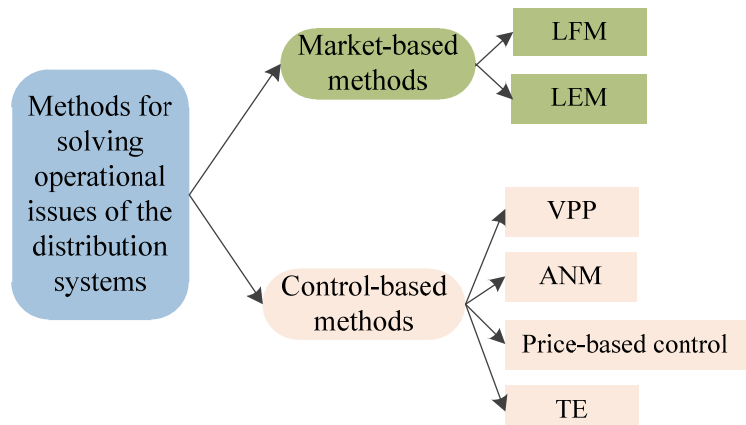

Fig. 11. Summary of studies on solving operational issues of the distribution systems due to high penetration of DERs.

Great achievements have already been made for solving operational issues of the distribution systems due to high penetration of DERs, which can be categorized into two streams, i.e., market-based methods and control-based methods. Market-based methods mainly include LFMs and LEMs. Control-based 
methods mainly include virtual power plants (VPPs), ANM, price-based control and TE systems. Fig. 11 summarizes these studies. These concepts and technologies are compared in this section.

\subsection{Market-based methods}

\subsection{1. $L F M$}

In the first stream, the LFM was designed and implemented to provide market tools for the DSO. More active system management and control can be realized for the DSO by trading flexibility in the designed LFM. Several studies in the literature have shown different methods for implementing LFM. LFM frameworks were proposed in [21], [33], [73] to solve operational problems for DSOs. A fix rate LFM was proposed in [64] to enable the DSO plan its system in a more economic way by using flexibility provided by flexible demands. The need for capacity expansion of a distribution system with the use of flexibility and without the use of flexibility were compared. A LFM framework was proposed in [72] to maximize the social welfare of participants in the LFM over the day-ahead scheduling horizon and intraday scheduling horizon. A decentralized LFM design was proposed in [77], which accounts for negotiations between DSO and aggregators, and negotiations between aggregators and prosumers as well. Torbaghan et al. [78] proposed a bi-level optimization framework, which provides a platform for local flexibility trading in both day-ahead market and intra-day market. The LFM can operate in parallel with the existent energy markets, e.g., day-ahead energy markets and intra-day energy markets [78], as shown in Fig. 12. A flexibility clearing house (FLECH) has been proposed, developed and demonstrated by the Danish iPower consortium [79]-[81].

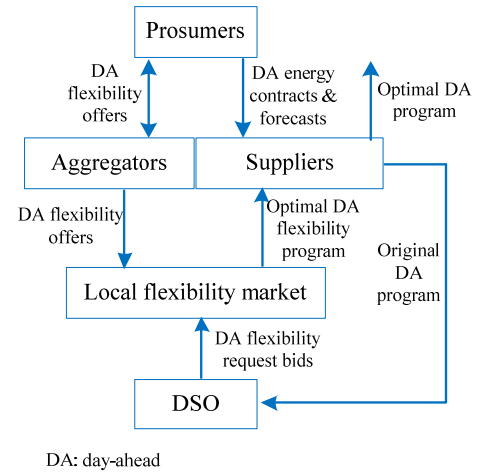

(a) Day-ahead markets;

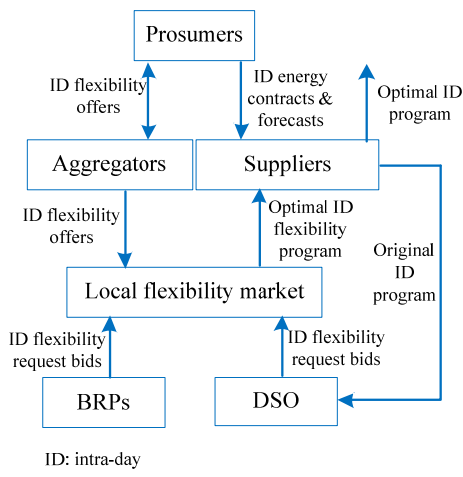

(b) Intra-day markets

Fig. 12. Parallel architecture of a LFM and the existing markets: (a) Day-ahead markets; (b) Intra-day markets (adopted from [78]).

\subsubsection{LEM}

In the second stream, the LEM was designed and implemented to manage the high penetration DERs by encouraging localized energy trading. Then, the operational issues of the distribution systems due to 
high penetration of DERs can be solved indirectly. The literature shows that more and more prosumers are willing to participate in LEM to trade energy locally [12], [83]-[84]. Khorasany et al. [12] presented a detailed review on the design and market clearing approaches for local energy trading. LEM is a wide market concept which can be characterized into different groups: (i) P2P energy trading [85]; (ii) Energy trading under supervision of a mediator [86]; (iii) Combination of (i) and (ii), where prosumers can trade energy directly or under supervision of a mediator [87]. The main advantage of P2P is that energy can be traded locally among prosumers without a central entity. However, P2P may lead to low negotiation power for prosumers when they trade energy with large stakeholders. For more details regarding the LFM, one can refer to [12].

\subsection{Control-based methods}

\subsection{1. $V P P$}

When the DERs are aggregated in a VPP, these DERs would have system visibility, controllability and impact like a conventional generator [88]. In this context, DERs can gain access and visibility across different energy markets through the VPP technologies. Furthermore, benefits for DSO (e.g., improved electric network efficiency and security, cost saving in distribution system, etc.) can be realized due to increased use of existing assets through the VPP technologies [89]. Different scheduling methods for VPPs were proposed in [90]-[94].

\subsection{2. $A N M$}

The ANM offers active and flexible control in voltage control, congestion management, and supply restoration in distribution systems. DSOs are adopting ANM to solve operational issues of the distribution systems due to high penetration of DERs controlling DERs, flexible demands and grid equipment in a centralized way [95]. An optimal scheduling method for a DSO, EV owners and the EV aggregators was proposed in [96]. By considering the grid constraints in the EV charging scheduling, the congestions and voltage violations can be solved. Two ANM techniques, i.e., dynamic line rating and DSM, were evaluated in [97] for congestion management of a distribution system from the DSO perspective. The active/reactive power control of DGs combined with the network reconfiguration were developed in [98] to minimize DG curtailment, alleviate congestions, and solve voltage violations of the distribution system due to DG integration. Several studies showed that various operational problems of distribution systems such as excessive power losses, grid congestions, over-voltage, low-voltage can be solved by controlling SOP in an optimal way [71], [99]-[101]. 


\subsubsection{Price-based control}

In price-based control methods, the DSO forecasts the potential congestions in certain durations and publishes the congestion price in advance to the flexible demands or their aggregators (who schedule the flexible demands in an optimal way). The distribution locational marginal price (DLMP) was employed in [102]-[103] to trigger the controllable DGs to alleviate congestion for distribution systems. The dynamic tariff (DT) methods were used in [62], [104]-[106] to solve congestion problems for distribution systems by motivating aggregators to shift the flexible demands from peak hours at specific nodes. Huang et al. [107] further proposed a distributed optimization-based dynamic tariff (DDT) method for congestion management in distribution systems that provided more certainty and transparency compared to the traditional DT method. A day-ahead congestion management method for distribution systems was proposed in [108], in which the DT was employed firstly to resolve the congestion and the re-profiling products (RPs) trading from the LFM were used afterwards to resolve the remaining congestion. A comprehensive method for day-ahead congestion management in distribution systems was proposed in [109] by integrating network reconfiguration, DT and RPs together.

\subsubsection{TE}

TE is widely used to manage the operation of DERs both in the literature and the industry. TE is defined as 'a set of economic and control mechanisms that allows the dynamic balance of supply and demand across the entire electrical infrastructure using value as a key operational parameter' by the GridWise Architecture Council [110]. TE uses decentralized decision-making framework, which shows its advantages in managing the operation of DERs [111]. Hu et al. [111] presented a detailed review on TE systems and TE control methods. A TE system was proposed in [30], [112] for managing the operation of constrained distribution systems, in which proper congestion prices were decided through the negotiation between the DSO and retailers. A TE framework was presented in [113], in which multiple smart buildings collaborate with each other in an aggregation of smart buildings. A distributed TE management method was proposed in [114] for multiple interconnected microgrids, in which optimal scheduling and fair energy trading of the multiple microgrids can be realized. For more details regarding the TE, one can refer to [111].

\subsection{Comparisons}

Control-based methods introduced in Section 3.2 are active control methods, which are designed from the point of view of DSOs. DSOs publish direct orders (which can be price signals or control commands) to the distribution systems and all the interconnected components for solving their operational problems. 
Market-based methods introduced in Section 3.1 provide trading platforms that enable the exchange of energy or flexibility services between buyers and sellers. Both participants, including the DSO and the prosumers, can benefit from participating in the markets. DSOs can also solve their operational problems by participating in the markets and trading relative energy or flexibility services. Therefore, the marketbased methods provide trading platforms rather than publish control orders in an active way.

In particular, LEMs, VPPs and TE systems can ensure that the consumers are empowered and protected in energy markets, which is actually the EU recommendation [21], [115]. One the contrary, ANM and price-based control are designed from the point of view of DSO, while LFMs provides a competitive platform where both participants, including the DSO and the prosumers, can benefit from.

In price-based control methods, a DSO forecasts the potential congestions in certain durations and publish the congestion price centrally to flexible demands or their aggregators. Then, the flexible demands or their aggregators accordingly schedule their resources. Therefore, the price-based control methods can lead to significant uncertainty in load profile due to the unconfirmed schedules of aggregators to the DSO [116]. The increased penetration of DERs would also make it more challenging to the DSO. Therefore, other methods are recommended to be employed together with the price-based methods to address this issue. For example, an ANM method (i.e., network reconfiguration) was employed together with a price-based control method (i.e., DT) in [106]; flexibility trading in LFM (i.e., trading RPs) was considered together with a price-based control method (i.e., DT) in [108]; a comprehensive method including an ANM method (i.e., network reconfiguration), flexibility trading in LFM (i.e., trading RPs) and a price-based control method (i.e., DT) was developed in [109].

ANM methods are based on centralized optimizations and are demonstrated to be accurate and effective. However, not all prosumers or aggregators connected to the distribution systems could be willing to share information. Meanwhile, the prosumers or aggregators are not allowed to get access to the grid parameters either grid status, because it is considered as confidential information. In this context, the effectiveness of the ANM based congestion management method cannot be guaranteed.

Compared to ANM methods, TE shows its advantages in managing the operation of DERs because it makes decision in a decentralized and transparent way [112]. However, TE could be less attractive for DSOs because there is no central entity looking after DSOs' requests, and multiple negotiations are also needed. Table 5 summarizes the comparisons among the different methods for solving operational problems of distribution systems.

Table 5

Comparisons among the methods for solving operational problems of distribution systems

\begin{tabular}{|c|c|c|c|c|c|}
\hline Ref. & $\begin{array}{l}\text { Market- } \\
\text { based } \\
\text { methods }\end{array}$ & Control-based methods & Viewpoint & Objective & Techniques \\
\hline
\end{tabular}




\begin{tabular}{|c|c|c|c|c|c|c|c|c|c|}
\hline & $\begin{array}{l}\mathrm{LF} \\
\mathrm{M}\end{array}$ & $\begin{array}{l}\text { LE } \\
\text { M }\end{array}$ & $\begin{array}{l}\text { VP } \\
P\end{array}$ & $\begin{array}{c}\mathrm{AN} \\
\mathrm{M}\end{array}$ & $\begin{array}{c}\text { Price- } \\
\text { based } \\
\text { contro } \\
1\end{array}$ & $\begin{array}{l}\mathrm{T} \\
\mathrm{E}\end{array}$ & & & \\
\hline$[8]$ & & $\sqrt{ }$ & & & & & Prosumers & $\begin{array}{c}\text { Maximize } \\
\text { prosumer's revenues } \\
\text { in P2P energy } \\
\text { trading }\end{array}$ & $\begin{array}{c}\text { Peer-to-peer } \\
\text { framework, } \\
\text { multi-agent } \\
\text { simulation }\end{array}$ \\
\hline$[10]$ & & $\sqrt{ }$ & & & & & $\begin{array}{c}\text { Prosumers/Mi } \\
\text { crogrid } \\
\text { operator }\end{array}$ & $\begin{array}{c}\text { Balance the } \\
\text { generation and } \\
\text { consumption locally }\end{array}$ & $\begin{array}{l}\text { Peer-to-peer } \\
\text { framework, } \\
\text { game theory }\end{array}$ \\
\hline$[11]$ & & $\sqrt{ }$ & & $\sqrt{ }$ & & & $\begin{array}{c}\text { DSO/Microgri } \\
\text { d operator }\end{array}$ & $\begin{array}{l}\text { Minimize the total } \\
\text { energy cost of the } \\
\text { community }\end{array}$ & $\begin{array}{l}\text { Peer-to-peer } \\
\text { framework, } \\
\text { rule-based } \\
\text { battery } \\
\text { control }\end{array}$ \\
\hline [13] & & & & $\sqrt{ }$ & & & $\begin{array}{l}\text { DSO/Microgri } \\
\text { d operator }\end{array}$ & $\begin{array}{l}\text { Minimize the total } \\
\text { energy cost of the } \\
\text { community }\end{array}$ & $\begin{array}{c}\text { Centralized } \\
\text { optimization } \\
\text {, model } \\
\text { predictive } \\
\text { control }\end{array}$ \\
\hline [14] & & & & $\sqrt{ }$ & & & DSO & $\begin{array}{l}\text { Minimize the total } \\
\text { energy cost of the } \\
\text { building } \\
\text { aggregators, reduce } \\
\text { power loss and } \\
\text { improve voltages of } \\
\text { the distribution } \\
\text { system }\end{array}$ & $\begin{array}{l}\text { Centralized } \\
\text { optimization } \\
\text {, second- } \\
\text { order cone } \\
\text { relaxation }\end{array}$ \\
\hline $\begin{array}{l}{[16],} \\
{[98]}\end{array}$ & & & & $\sqrt{ }$ & & & DSO & $\begin{array}{l}\text { Minimize the day- } \\
\text { ahead operational } \\
\text { cost of the DSO }\end{array}$ & $\begin{array}{l}\text { Network } \\
\text { reconfigurat } \\
\text { ion }\end{array}$ \\
\hline $\begin{array}{l}{[21],} \\
{[33]}\end{array}$ & $\sqrt{ }$ & & & & & & DSO & $\begin{array}{l}\text { Minimize the } \\
\text { operation cost of the } \\
\text { LFM operator of } \\
\text { meeting a request } \\
\text { from the DSO }\end{array}$ & $\begin{array}{r}\text { Centralized } \\
\text { optimization }\end{array}$ \\
\hline $\begin{array}{l}{[25],} \\
{[62],} \\
{[104]}\end{array}$ & & & & & $\sqrt{ }$ & & DSO & $\begin{array}{l}\text { Generate a proper } \\
\text { price signal for the } \\
\text { aggregators for }\end{array}$ & DT method \\
\hline$[107]$ & & & & & & & & $\begin{array}{c}\text { DSO's congestion } \\
\text { management }\end{array}$ & \\
\hline $\begin{array}{l}{[30],} \\
{[112]}\end{array}$ & & & & & & $\sqrt{ }$ & DSO & $\begin{array}{c}\text { Minimize the } \\
\text { operational cost of } \\
\text { DERs and power } \\
\text { losses, as well as } \\
\text { preventing } \\
\text { congestion and } \\
\text { voltage violation } \\
\text { problems }\end{array}$ & $\begin{array}{l}\text { Network- } \\
\text { constrained } \\
\text { TE control } \\
\text { method }\end{array}$ \\
\hline [47] & & $\sqrt{ }$ & & & & & Prosumers & $\begin{array}{l}\text { Maximize the } \\
\text { summation of } \\
\text { welfares of all the } \\
\text { generation and } \\
\text { consumer units }\end{array}$ & $\begin{array}{c}\text { Cooperative } \\
\text { distributed } \\
\text { algorithm }\end{array}$ \\
\hline [49] & & & & $\sqrt{ }$ & & & DSO & $\begin{array}{c}\text { Solve voltage } \\
\text { violations in } \\
\text { distribution systems } \\
\text { due to high } \\
\text { penetration of PV }\end{array}$ & $\begin{array}{l}\text { Consensus } \\
\text { algorithm }\end{array}$ \\
\hline
\end{tabular}


[64] V

[68]

[71],

[99]-

[101]

[72]

[73] V

[77] $\quad \sqrt{ } \quad \sqrt{ }$

[78]-

[81]

[86]

[88]-

[94]

[96]
DSO,

prosumers

DSO

DSO

$\checkmark$

DSO

$\sqrt{ }$

DSO

Social welfare

Aggregator

DSO

DSO

Microgrid

Prosumers,

DERs

DSO
Remove congestions

from distribution systems using

energy and reserve form buildings

Generate a proper price signal for the EV aggregators for DSO's congestion management

Minimize the cost of procuring

flexibility, which enables the DSO to plan its system in a more economic way

Solve the voltage rise/drop issue in distribution systems due to high penetration of $\mathrm{PV}$

Reduce power loss, balance feeder load and improve voltage profile

Maximize the social welfare in the LFM Minimize the operation cost of the aggregator of meeting a request from the DSO

Enable the DSO to manage local demand constraints by using flexibility provided by aggregators

Minimize the cost of procuring flexibility for the DSO for operational purposes Propose a contribution-based energy trading mechanism to encourage providers to donate energy Enhance the visibility and control of system operators and market participants to DERs and prosumers Avoid congestions due to EVs charging
DLMP, iterative

DLMP, dual

decompositi

on

DT method,

DC optimal

power flow

Centralized

optimization

Three

control

strategies:

constant set-

point, time-

based and

remote

monitoring-

based

Optimal

operation of SOP

Centralized

optimization

Centralized

optimization

Multi-agent control,

peer-to-peer

framework

Bi-level

optimization

, centralized

optimization

Noncoopera

tive energy

competition

game

Centralized optimization

, stochastic

programmin

$\mathrm{g}$

Centralized approach of 


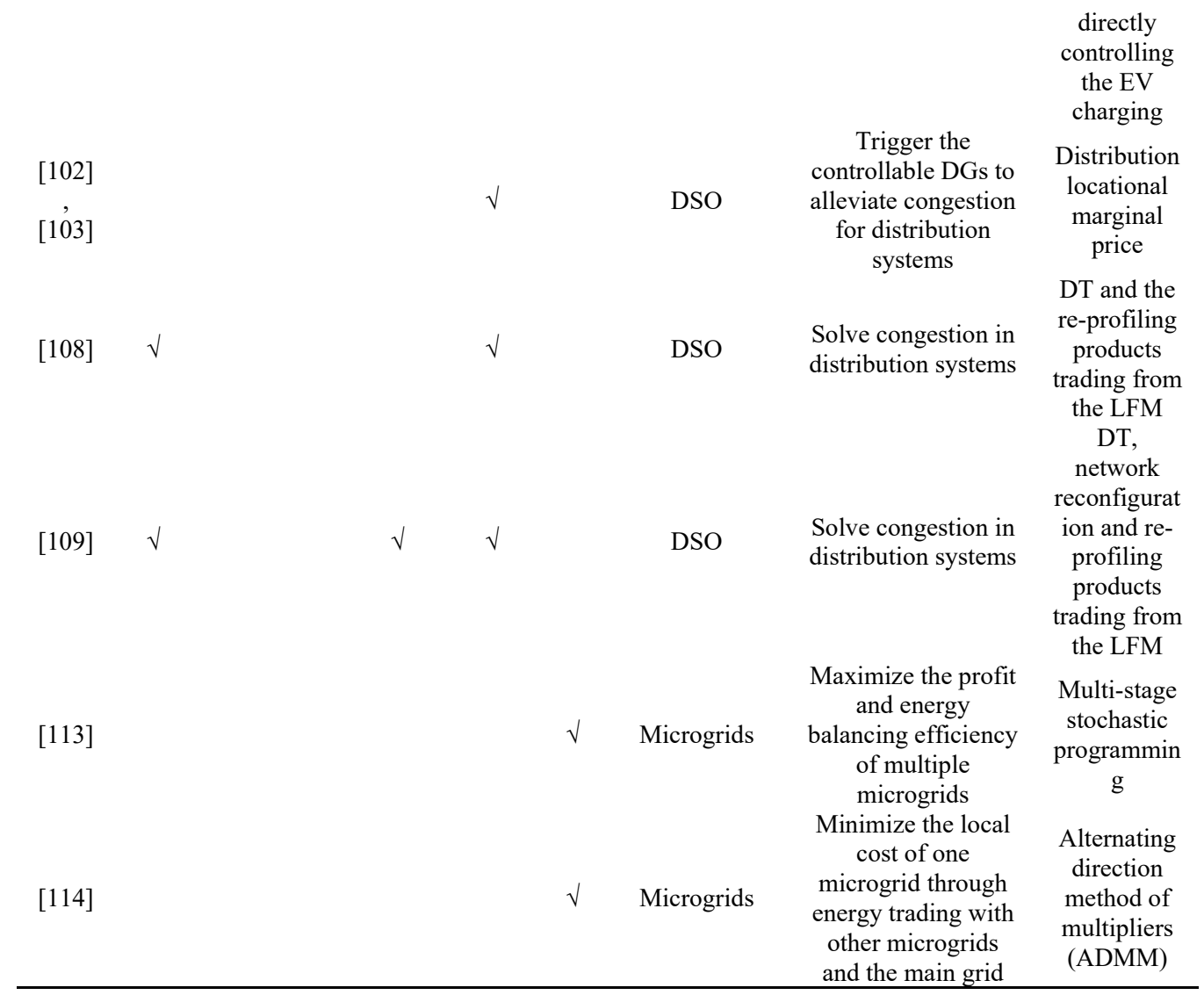

\section{Models of local flexibility market and its market design}

A LFM involves the interaction between different participants, and thus their behaviors should be mathematically modelled. Different formulations proposed in the literature can be classified into four different categories, i.e., centralized optimization models from viewpoint of one participant, game theory-based models, auction theory-based models and simulation models. Each category can be classified further into specific models, as shown in Fig. 13. 


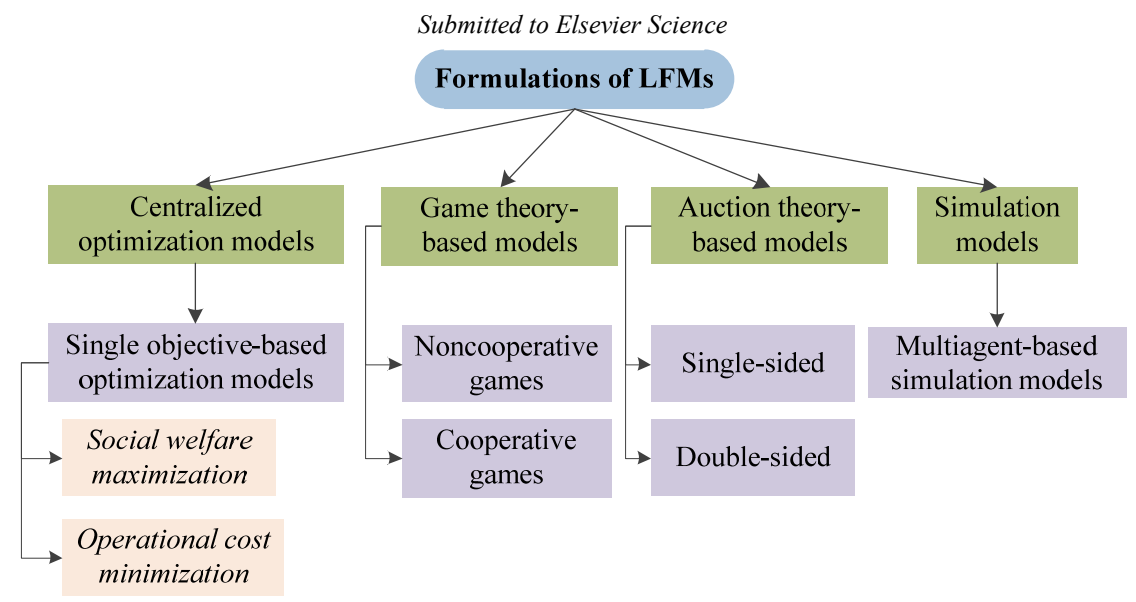

25

Fig. 13. Summary of formulations of LFMs.

\subsection{Centralized optimization models}

The LFM can be formulated as a centralized optimization model and the market is cleared by solving this optimization problem. The optimization problem is normally formulated as an objective function to be optimized, which is subject to a set of technical and economic constraints. According to the objectives, this kind of LFM formulations can also be classified into two streams: social welfare maximization and operational cost minimization.

\subsubsection{Social welfare maximization}

From the social perspective, social welfare maximization is considered as the optimization objective of LFM clearing. In LFM, the social welfare can be modelled as the sum of the cost of procuring flexibility minus the cost of providing flexibility [72]. Social welfare maximization aims to maximize the total social welfare of the market participants in the LFM, as shown in Eq. (1). The participants in the LFM are assumed to be a DSO and several aggregators. Eq. (1) is formulated to determine an aggregated flexibility profiles provided by aggregators, which maximizes the social welfare.

$$
\max S=\sum_{t \in \Omega_{t}}\left[B_{t^{-}} C_{t}\right]
$$

Where $S$ is the aggregated social welfare; $B_{t}$ is the cost of procuring flexibility for the DSO, which can be calculated by Eq. (2); $C_{t}$ is the cost of providing flexibility offers of aggregators, which can be calculated by Eq. (3). The symbols and notations are defined in [72] and also listed in

Table 6.

$$
\begin{gathered}
B_{t}=\beta_{d}\left|\rho_{d} \times q_{d}^{t}\right|, \quad \forall t \in \Omega_{t} \\
C_{t}=\sum_{a \in \Omega_{A}} \sum_{p a \in \Omega_{a}^{p}} \beta_{a}^{p a} \cdot\left|\rho_{a}^{p a} \times q_{a}^{p a, t}\right|, \quad \forall t \in \Omega_{t}, \forall a \in \Omega_{A}, p a \in \Omega_{a}^{p}
\end{gathered}
$$


Table 6

Summary of symbols and notations in the formulation of social welfare maximization, which are adopted from [72].

\begin{tabular}{cl}
\hline Symbol & \multicolumn{1}{c}{ Definition } \\
\hline$\Omega_{t}$ & Set of indexes of all programmable time units (PTUs) included in the scheduling horizon. \\
$\Omega_{A}$ & Set of indexes of all aggregators. \\
$\Omega_{a}^{p}$ & Set of indexes of all flexibility offer profiles of the $a$ th aggregator. \\
$d$ & Index to refer to the DSO. \\
$p a$ & Index to refer to the $p$ th profile of the $a$ th aggregator. \\
$\beta_{d}$ & Binary variable associated with the DSO's request getting accepted or rejected. \\
$\beta_{a}^{p a}$ & Binary variable associated with the profile $p a \in \Omega_{a}^{p}$ of aggregator $a \in \Omega_{A}$ being accepted or rejected. \\
$q_{d}^{t}$ & Amount of flexibility the DSO requests from the LFM at every PTU in its single request profile. \\
$\rho_{d}$ & Price of the flexibility request profile of the DSO. \\
$q_{a}^{p a, t}$ & Amount of flexibility that the $a$ th aggregator offers in its path profile during $t$ th PTU. \\
$\rho_{a}^{p a}$ & Price of the $p a$ th flexibility offer profile of the $a$ th aggregator. \\
\hline
\end{tabular}

\subsubsection{Operational cost minimization}

From one participant's viewpoint in the LFM, e.g., the DSO, it is desired to minimize the operational cost for procuring flexibility in the LFM. In this case, the objective of LFM clearing can be considered as the minimization of the DSO's cost for procuring flexibility, as shown in Eq. (4). It is worth noting that the objective can also be considered as the minimization of other participants' operational cost, such as minimization of the LFM operator's operational cost in [21], [33]; minimization of the DSO's operational cost in [64], [78], [79]-[81]; minimization of the aggregator's operational cost in [73].

$$
\min B_{t}=\beta_{d}\left|\rho_{d} \times q_{d}^{t}\right|, \quad \forall t \in \Omega_{t}
$$

\subsection{Game theory-based models}

Game theory is a mathematical tool to analyze strategies in competitive situations where the outcome of a participant's choice of action depends on the actions of other participants [117]. Different to the centralized optimization models, the game theory-based models represent the overall market behavior considering competitions among all participants. In this context, the profits of all the participants competing in the market are maximized in the formulations. The game theory-based models can be divided into two streams: noncooperative game theory and cooperative game theory. The cooperative game is a competition between players with cooperative behaviors, whereas players make decisions independently in the noncooperative game.

\subsubsection{Noncooperative game theory}

Players in a noncooperative game have partially or totally conflicting interests in the outcome of the decision-making process, which is also impacted by the players' actions [117]. A noncooperative game allows players to make decisions and take actions without any coordination or communication with other 
players. Noncooperative game theory were wildly used to formulate local energy trading ${ }^{3}$ in the literature. Noncooperative game theory-based formulations were presented in [10], [118], [119] to analyze market participants' behaviors in a P2P market, and the best solution was obtained using Nash equilibrium. Nikaido-Isoda relaxation algorithm was used in [120]-[121] to convert the game theory-based models into optimization problems, which can be solved easily. Stackelberg game theory-based models with multi-leaders and multi-followers were proposed for energy trading among multiple microgrids in [122] and for energy trading in the integrated energy systems in [123]. A Stackelberg game approach was utilized in [124] to analyze the trade-off between the retail profit and the consumer surplus. A bilevel optimization problem based on Stackelberg game approach was further developed in [125].

\subsubsection{Cooperative game theory}

A cooperative game is a mathematical tool to analyze the interactions of rational cooperative players with cooperative behaviors [126]. In [127], a demand response scheme was proposed based on cooperative game theory to reduce the electricity costs of industrial refrigerated warehouses. In [128], cooperative game theory was utilized to form an energy grand coalition, where the operations of energy storage system were optimized to minimize the coalitional energy cost. In [129], a direct electricity trading method was developed to facilitate local energy trading, in which a higher joint revenue was demonstrated through cooperative game theory.

\subsection{Auction theory-based models}

Auction is an economic resource allocation mechanism which aims to balance supply and demand through a competitive bidding process [130]. Identical to economic auctions, the focus of auctions in energy markets is to find the minimum cost, which balances supply and demand with maximize economic efficiency [131]. Auction theory-based models can be classified into single-side auction models and double-side models, as shown in Fig. 14. In a single-sided forward auction, several buyers bid for an item being sold, while several sellers offer an item that a buyer request in a single-sided reverse auction. On the contrary, several buyers bid to buy goods from several sellers in a double-sided auction.

\footnotetext{
${ }^{3}$ Game theory-based models for LFMs are similar to that for LEMs. Therefore, game theory-based models for LEMs are reviewed in this paper due to limited published work using game theory-based models for LFMs in the literature. The same situation applies to auction theory-based models and simulation models introduced in Section 4.3 and Section 4.4 as well.
} 


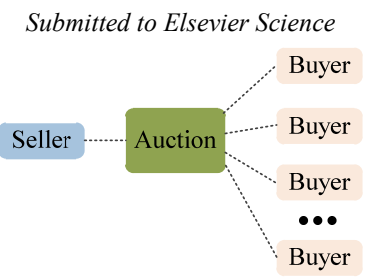

(a) Single-sided auction: forward auction where several buyers bid for an item being sold

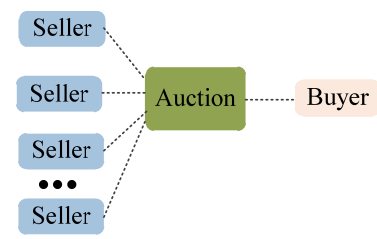

(b) Single-sided auction: reverse auction where several sellers offer an item that a buyer request

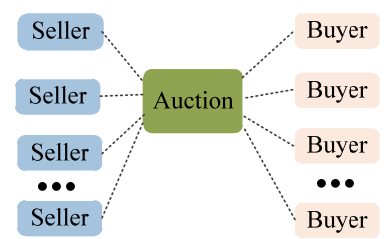

(c) Double-sided auction: several buyers bid to buy goods from several sellers

Fig. 14. Classification of auction theory-based models.

The single-sided auction model is not suitable for local flexibility or energy trading, because a LFM or a LEM normally includes multiple buyers and sellers. Both multiple buyers and multiple sellers can be are involved in double-sided auctions. Therefore, double-side auction models were used for modelling LEMs in the literature. Zaidi et al. [131] developed a double-sided auction mechanism for local energy trading among multiple microgrids and similar double-sided auction mechanism was designed in [132] for energy trading among different energy entities in a multi-energy systems. An iterative double auction mechanism was proposed in [133] to maximize social welfare of EVs in a localized P2P energy market. In [134], an auction mechanism for truthful energy trading in a LEM was proposed, which was developed based on the Vickrey-Clarke-Groves auction.

\subsection{Simulation models}

As a flexible modelling framework, multiagent-based modelling tools can analyze new paradigms in the field of smart grids and efficient market integrations [135]. The applications of multiagent-based modelling on the field of smart grids were reviewed in [135] and [136]. As defined in [137], an agent is "a software (or hardware) entity that is placed in some environment and is able to autonomously react to the changes in that environment". Therefore, multiagent-based modeling is suitable to model energy markets with multiple participants, in which each participant can be considered as an agent. Each agent can be a single variable in a computer program or a smart object with an infinite number of actions and decisions [12]. Multiagent-based models were wildly used to formulate local flexibility and energy 
trading in the literature. A multiagent-based LFM was designed in [77], which allows the DSO to manage local demand constraints by obtaining flexibility from competing aggregators. A multiagent-based LEM model was proposed in [138] for multiple microgrids with agents delegating DGs, loads, energy storage systems in the market. A multiagent-based modelling approach was presented in [139] to simulate energy trading between two energy communities. In [140], a multiagent-based energy trading platform was proposed to facilitate the energy storage systems' participations in LEMs. A cooperative control framework for the coordinated operations of multiple microgrids was proposed in [141] using multiagent-based modelling method, which was then extended by [142] to a two-layer structure to facilitate the P2P electricity sharing amongst prosumers using blockchain technologies. A multiagentbased LEM model was proposed in [143], in which a DSO, multiple aggregators and prosumers can trade energy efficiently. The classification of different models is shown in Table 7.

Table 7

Classification of market formulations

\begin{tabular}{|c|c|c|}
\hline \multicolumn{2}{|c|}{ Formulation } & Ref. \\
\hline \multirow[b]{2}{*}{$\begin{array}{l}\text { Centralized optimization } \\
\text { models }\end{array}$} & Social welfare maximization & {$[72]$} \\
\hline & Operational cost minimization & $\begin{array}{l}\text { Viewpoint of LFM operator: }[21],[33] ; \\
\text { Viewpoint of DSO: }[64],[78],[79]-[81] ; \\
\text { Viewpoint of aggregator: [73]. }\end{array}$ \\
\hline Game theory-based models & $\begin{array}{c}\text { Noncooperative game theory } \\
\text { Cooperative game theory }\end{array}$ & $\frac{[10],[118],[119],[120]-[125]}{[126]-[129]}$ \\
\hline \multicolumn{2}{|c|}{ Auction theory-based models } & {$[131]-[134]$} \\
\hline \multicolumn{2}{|c|}{ Simulation models } & {$[12],[77],[138]-[143]$} \\
\hline
\end{tabular}

\subsection{Comparisons}

Game theory-based models, auction theory-based models and simulation models can simulate market behaviors in a more accurate way because these models can represent all the participants in the market. Particularly, the multiagent-based models are flexible to consider agents with separate resources, private or public information, and different strategies. On the contrary, centralized optimization models only represent one participant or the social welfare. The comparison between the single objective-based optimization formulation and the game theory-based formulation is shown in Fig. 15.

The centralized optimization models and game theory-based models have certain conceptual overlaps. The centralized optimization models can be used to analyze the game theory-based models, which has been demonstrated in the literature. Linear programming is useful for solving zero-sum two-person games [144]. Nash Equilibrium can be found iteratively by mixed-integer linear programming (MILP) [145] and relaxation algorithms (e.g., Nikaido-Isoda relaxation algorithm used in [120]-[121]). Wang et al. [146] established the Karush-Kuhn-Tucker (KKT) conditions of the non-cooperation game model, in which the Nash Equilibrium was found by solving the KKT conditions simultaneously. 


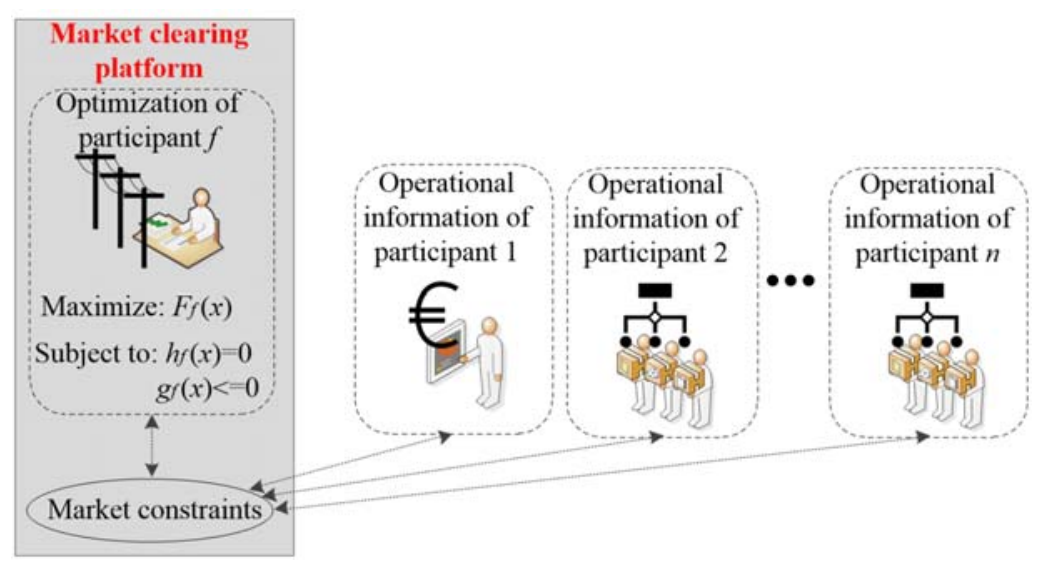

(a) Single objective-based optimization models for market clearing

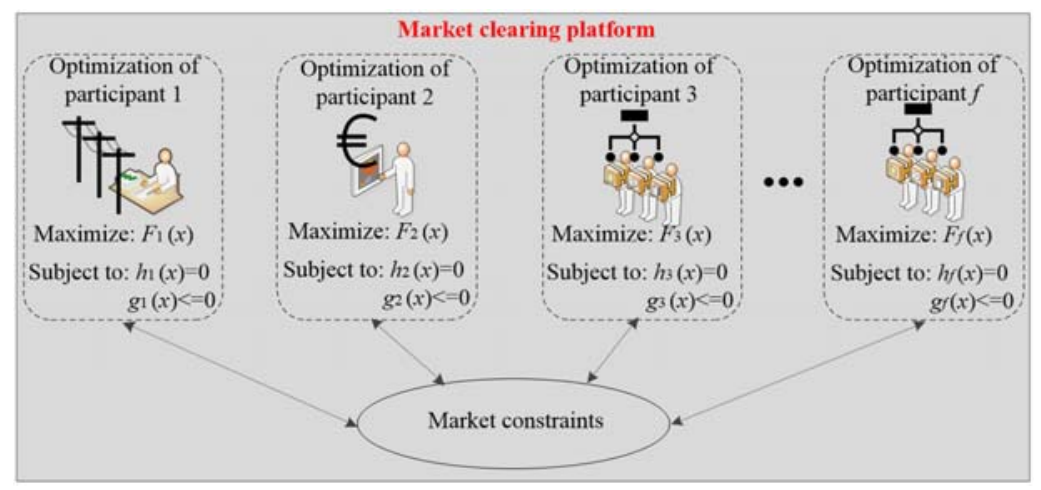

(b) Game theory-based models for market clearing

Fig. 15. Comparison between the single objective-based optimization formulation and the game theory-based formulation.

The centralized optimization models and multiagent-based models also have certain conceptual overlaps. Each agent represents a behavioral model which can be a complex optimization model or a simple set of fixed rules [135]. Therefore, optimization models can be used to model the behaviors of one agent in the multiagent-based models. Shafie-Khah et al. [147] developed a multiagent-based electricity market model, in which each market participant is individually modeled as an agent that maximizes the participant's benefit. A multiagent-based retail electricity market was modelled in [148] with the retailer agent maximizing its profit and air conditioning agent optimizing users' energy consumption within their comfort ranges.

The centralized optimization models are easy to implement compared to other models. However, they have barriers for large-scale systems due to scalability limits. One the contrary, market designs with game theory-based models, auction theory-based models and simulation models are more scalable, which could be applied for markets where huge number of players are participating in. Rassaei et al. [149] proposed a distributed game theory-based method for managing large number of EVs' participations in energy markets. The scalability of proposed method was proved. Pourbabak et al. [150] showed the good 
scalability of the multiagent-based model, which can solve problem with more than 1000 agents consuming limited computing time.

\section{Solution approaches}

The concept and formulations of LFMs have been discussed in Section 2 and Section 4. In this section, the solution methods that are used to clear LFMs are reviewed. The employed approaches can be divided into four categories depending on assumptions, market structures, behaviors of market players, and rules of the market ${ }^{4}$. These categories are illustrated in Fig. 16.

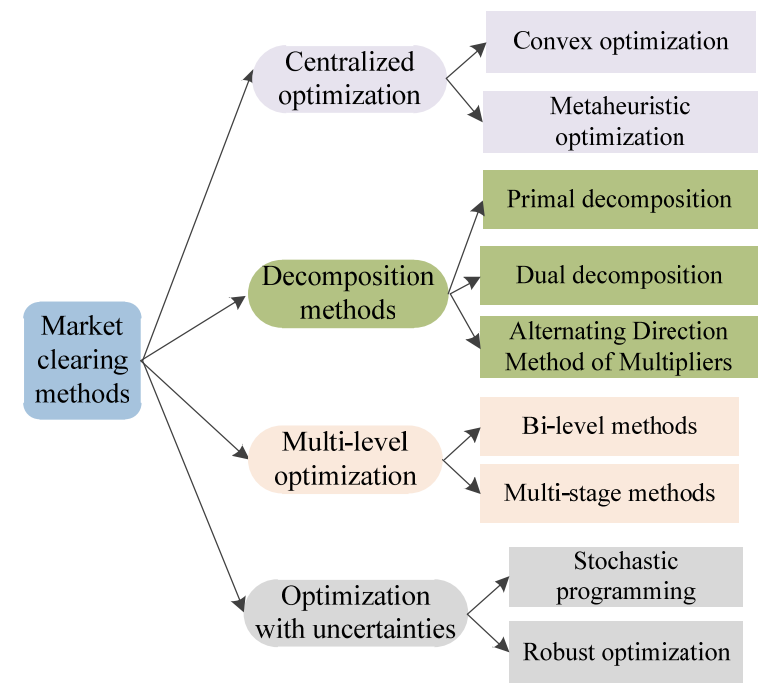

Fig. 16. Summary of solutions for market clearing of LFMs.

\subsection{Centralized optimization}

Centralized optimization is an optimization program running over a specified time horizon, where a specific algorithm is used to search for an optimal value to minimize or maximize the objective function. It has been demonstrated promising for clearing local markets in the literature, where single objective functions are optimized with various constraints. Convex optimization is the most commonly used centralized optimization in the literature. Relaxation techniques are also employed for transferring nonconvex optimization problems to convex optimization problems. Metaheuristic methods are also used for centralized optimization.

${ }^{4}$ Clearing methods for LFMs are similar to that for LEMs. Therefore, clearing methods for LEMs are also reviewed together with LFMs in this paper. 


\subsubsection{Convex optimization}

The summary of four different types of convex optimization, i.e., linear programming (LP), MILP, mixed integer non-linear programming (MINLP), second-order cone programming (SOCP), quadratic programming (QP), is shown in Table 8 . These convex optimization methods are used for clearing local markets depending on the formulations of the markets. The formulations can be centralized optimization models or centralized optimization models converted from other models (e.g., game theory-based models, auction theory-based models and multiagent-based models).

In [151], the optimal capacity of various DERs was decided using LP to balance the local demand and supply in a P2P market. MILP was used in [21], [64], [72], [73], [81] to clear LFMs and used in [8] and [47] for a P2P market. A MINLP was carried out in the first stage of a P2P market in [11] to minimize the total energy cost of the community. The non-convex optimization problem was relaxed to a SOCP problem in [152] to clear a P2P market considering the network constraints of a distribution system. Liu et al. [153] proposed an EV charging scheduling method based on an aggregative game model in dayahead electricity market, in which the unique Nash Equilibrium is determined through QP.

Table 8

Classification of convex optimizations

\begin{tabular}{|c|c|c|c|}
\hline $\begin{array}{c}\text { Convex } \\
\text { optimization }\end{array}$ & Features & Model equations & Ref. \\
\hline & & $\min f=\boldsymbol{c}^{T} \boldsymbol{x}$ & \\
\hline LP & The objective and constraints are linear & $\begin{aligned} \text { s.t. } \boldsymbol{G} \boldsymbol{x} & \leq h \\
\boldsymbol{A} \boldsymbol{x} & =b\end{aligned}$ & {$[151]$} \\
\hline MILP & $\begin{array}{l}\text { The objective and constraints are linear; all } \\
\text { or some variable within the set of integers } \\
\qquad \mathbb{Z}\end{array}$ & $\begin{array}{l}\min f=\boldsymbol{c}^{T} \boldsymbol{x} \\
\text { s.t. } \boldsymbol{G} \boldsymbol{x} \leq h \\
\quad \boldsymbol{A} \boldsymbol{x}=b \\
\quad x_{i} \in \mathbb{Z}\end{array}$ & $\begin{array}{l}{[8],[21],[47],} \\
{[64],[72],[73],} \\
{[81]}\end{array}$ \\
\hline MINLP & $\begin{array}{l}\text { Same formulation as in MILP, with some } \\
\text { or all the equations being non-linear and } \\
\text { convex }\end{array}$ & $\begin{array}{l}\min f=\boldsymbol{c}^{T} \boldsymbol{x} \text { (non-linear) } \\
\text { s.t. } \boldsymbol{G} \boldsymbol{x} \leq h \\
\quad \boldsymbol{A} \boldsymbol{x}=b \quad \text { (non-linear) } \\
\quad x_{i} \in \mathbb{Z}\end{array}$ & [11] \\
\hline \multirow{3}{*}{ SOCP } & \multirow{3}{*}{$\begin{array}{l}\text { In a SOCP, a linear function is minimized } \\
\text { over the intersection of an affine set and } \\
\text { the product of second-order (quadratic) } \\
\text { cones }\end{array}$} & $\min f=\boldsymbol{c}^{T} \boldsymbol{x}$ & \multirow{3}{*}{ [152] } \\
\hline & & $\begin{array}{c}\text { s.t. } \boldsymbol{A} \boldsymbol{x}=b \\
x_{i} \in H, i=1,2, \ldots, N \\
\text { second-order cone: } \\
H=\left\{x_{i} \in R_{N} \mid y^{2} \geqslant \sum_{i=1}^{N} x_{i}^{2} ; y \geqslant 0\right\}\end{array}$ & \\
\hline & & $\begin{array}{c}\text { rotating second-order cone: } \\
H=\left\{x_{i} \in R_{N} \mid y z \geqslant \sum_{i=1}^{N} x_{i}^{2} ; y, z \geqslant 0\right\}\end{array}$ & \\
\hline
\end{tabular}




$$
\begin{array}{llr}
\text { If the objective function of a QP problem } & \min (1 / 2) \boldsymbol{x}^{T} \boldsymbol{P} \boldsymbol{x}+\boldsymbol{q}^{T} \boldsymbol{x} \\
\text { is quadratic (convex) and its constraints } & \text { s.t. } \boldsymbol{G} \boldsymbol{x} \leq h \\
\text { are affine, it could be a convex problem } & \boldsymbol{A} \boldsymbol{x}=b
\end{array}
$$

\footnotetext{
Where $\boldsymbol{x}$ is the vector of the optimization variables; $\boldsymbol{c}, \boldsymbol{G}$ and $\boldsymbol{A}$ are vectors; $b$ and $h$ are scalar matrices; $\mathbb{Z}$ denotes the set of integer numbers; $\boldsymbol{P}$ and $\boldsymbol{q}$ are vectors belong to the set of real numbers.
}

\subsubsection{Metaheuristic optimization}

Heuristic methods for centralized optimization were widely used in the literature. A genetic algorithm (GA) was implemented in [33] to clear a LFM. Table 9 summarizes several normally used metaheuristic algorithms for centralized optimization.

Table 9

\begin{tabular}{|c|c|c|}
\hline $\begin{array}{l}\text { Metaheuristic } \\
\text { algorithms }\end{array}$ & Mechanism & Source \\
\hline $\begin{array}{c}\text { Genetic algorithm (GA) } \\
{[33]}\end{array}$ & $\begin{array}{c}\text { A GA evolves a population of candidate solutions } \\
\text { initialized randomly in the search space to precede to the } \\
\text { global optimum through selection, crossover and } \\
\text { mutation operators. }\end{array}$ & $\begin{array}{l}\text { Imitate the theory of Darwinian } \\
\text { evolution }\end{array}$ \\
\hline $\begin{array}{c}\text { Particle swarm } \\
\text { optimization (PSO) } \\
{[154]}\end{array}$ & $\begin{array}{l}\text { Each agent has a velocity and position vector, which are } \\
\text { updated according to the best so far positions of particle } \\
\text { and population over the course of evolution. }\end{array}$ & $\begin{array}{l}\text { Imitate the foraging behavior of } \\
\text { bird flocking }\end{array}$ \\
\hline $\begin{array}{l}\text { Differential evolution } \\
\quad \text { (DE) [155] }\end{array}$ & $\begin{array}{l}\text { DE also employs mutation, crossover and selection to } \\
\text { generate new candidates according to the difference } \\
\text { between pairs of solutions used for searching a moving } \\
\text { direction. }\end{array}$ & $\begin{array}{c}\text { Originally proposed by Storn and } \\
\text { Price }\end{array}$ \\
\hline $\begin{array}{l}\text { Simulated annealing } \\
\quad \text { (SA) [156] }\end{array}$ & $\begin{array}{l}\text { SA has been incorporated into different frameworks for } \\
\text { dealing with optimization problems. }\end{array}$ & $\begin{array}{l}\text { A single-point-based global } \\
\text { optimization technique which was } \\
\text { inspired by annealing in metallurgy }\end{array}$ \\
\hline $\begin{array}{l}\text { Artificial bee colony } \\
\quad(\mathrm{ABC})[157]\end{array}$ & $\begin{array}{c}\mathrm{ABC} \text { is an optimization algorithm based on the } \\
\text { intelligent foraging behavior of honeybee swarm. The } \\
\text { colony consists of three groups of bees: employed bees, } \\
\text { onlookers and scouts. }\end{array}$ & $\begin{array}{l}\text { ABC belongs to the group of } \\
\text { swarm intelligence algorithms and } \\
\text { was proposed by Karaboga in } 2005\end{array}$ \\
\hline $\begin{array}{l}\text { Teaching learning- } \\
\text { based optimization } \\
\text { (TLBO) [158] }\end{array}$ & $\begin{array}{l}\text { TLBO mimics the teaching-learning ability of the } \\
\text { teacher and learners in a classroom. The teacher and } \\
\text { learners are the two vital components of the algorithm. }\end{array}$ & $\begin{array}{l}\text { Inspired from the interaction } \\
\text { among students and teacher in a } \\
\text { classroom }\end{array}$ \\
\hline
\end{tabular}

Summary of metaheuristic algorithms

\subsection{Decomposition methods}

It is challenging to apply the centralized optimization methods on large-scale systems due to high computation overheads. Therefore, decomposition methods are wildly applied on market clearing in the literature [12]. Decomposition method breaks the original problem into smaller subproblems. Then, each subproblem is solved independently. The overall computational burden can be decentralized and allocated to each sub-problem. There are many decomposition methods applied in the field of optimization of power systems and energy markets. This paper reviews three commonly used decomposition methods for clearing local markets below. 


\subsubsection{Primal decomposition}

In primal decomposition, the master problem assigns energy to the subproblems (market players) and then each player optimizes its objective to find the best value with the allocated energy [12]. Benders decomposition is a classic primal decomposition method [159], which is widely used in the literature. Zheming et al. [160] proposed an optimal bidding method for a VPP in pool-based energy markets, where the Benders decomposition method was carried out to efficiently solve the optimization problem. Ghasemi et al. [161] proposed an optimal bidding method for a DSO in day-ahead energy markets, where the Benders decomposition method was employed to decompose the original optimization problem. Monfared et al. [162] proposed a dynamic retail electricity pricing strategy, in which the Benders decomposition method was implemented to simplify the primary MINLP problem.

\subsubsection{Dual decomposition}

As pointed out in [12], a dual variable is propagated by the master problem to the subproblems in the dual decomposition method. Then, each player optimizes its operation considering corresponding operational cost and resource cost in each subproblem. Samadi et al. [163] proposed a dual decomposition-based pricing strategy to determine prices in a distributed way and maximize the benefits of suppliers while minimizing the cost of consumers. Deng et al. [164] used dual decomposition to decompose a multiseller-multibuyer problem to single-seller-multibuyer subsystems. Then, the demand response problem in each subsystem was solved in a distributed way. A Dantzig-Wolfe decompositionbased clearing method for a real-time LEM was proposed in [165]. A real-time pricing mechanism was proposed in [166], in which the supply-demand balance was guaranteed by explicitly considering the equality constraint through dual decomposition.

\subsubsection{Alternating Direction Method of Multipliers (ADMM)}

ADMM is an augmented Lagrangian relaxation-based algorithm that breaks convex optimization problems into smaller pieces to solve them in an easier way [167]. ADMM combines the decomposability of the dual ascent method and the convergence property of upper bound of the methods of multipliers. It can be treated as another version of the method of multipliers, where each primal variable's optimization was conducted in successive steps [167]. Therefore, ADMM has good robustness of multipliers, which can also support decomposition and is reviewed in this paper. ADMM was used in [168] to clear a multiarea energy market for wind-integrated interconnected power systems. Loukarakis et al. [169] proposed an ADMM-based clearing method for decentralized energy markets. The convergence performance of the proposed ADMM-based method with different decomposition granularity was also demonstrated. 
Nguyen et al. [170] proposed an ADMM algorithm for solving the dynamic social welfare maximization problem and for deriving a real-time pricing scheme to facilitate autonomous demand response. The computational properties of the ADMM-based market clearing algorithm for a P2P market was assessed in [171].

It is worth noting that game theory-based market models, auction theory-based market models and simulation models can be solved by converting original models into optimization models using iterative and relaxation techniques, as introduced in Section 4.5. Then, these models can be cleared using convex optimization or decomposition methods depending on their specific formulations.

\subsection{Multi-level optimization}

Multi-level optimization methods are also used for market clearing in the literature. The main focus of multi-level optimization is on dividing the problem into several sections at several levels and assigning each section an optimization problem. A bi-level optimization method was presented in [81] to clear a LFM both in day-ahead stage and intra-day stage. Rastegar et al. [172] proposed a bi-level optimization method for a distribution system in day-ahead market. A bi-level optimization method was developed in [173] to clear a retail energy market where a retailer and consumers are trading energy. Ottesen et al. [174] proposed a multi-stage decision-support model to solve the scheduling and bidding problems for aggregators in several sequential energy markets.

\subsection{Optimization with uncertainties}

Optimization methods with uncertainties have been used to address the uncertainties (e.g., intermittent renewable generations, load variation, market prices, etc.) in local markets. The optimization with uncertainties can be divided into two streams depending on the formulation of uncertain variables: stochastic programming and robust optimization [175].

\subsubsection{Stochastic programming}

In stochastic programming, uncertainty is normally characterized by a probability distribution function on the parameters. The objective function is usually formulated as the expected function, which is then optimized using stochastic programming. Different stochastic programming methods are used to clear local markets in the literature, which can be summarized as follows.

(1) Scenario-based method

Uncertainties are described as discrete scenarios in scenario-based methods. The scenarios are generated using the probability distribution functions of the uncertainties. To guarantee the accuracy in stochastic programming, the number of scenarios shall be large. Then, scenario reduction techniques are 
usually carried out to reduce the number of scenarios and the computational burden of the problem [176]. A bi-level stochastic programming method was proposed in [177] for a retailer trading market. Liu et al. [178] proposed a P2P energy trading model, in which each prosumer solved a bi-level stochastic programming problem locally to find a fixed pricing strategy for each prosumer with minimum expected cost.

(2) Chance-constrained method

Chance-constrained method is another stochastic programming, which relaxes the constraints with a predefined small probability. Zachar et al. [179] proposed an energy exchange commitment method for a microgrid in day-ahead market. Chance-constrained method was used to minimize the operational cost of the microgrid. A DLMP method using chance-constrained optimization was developed in [180] to alleviate the potential congestions in distribution systems with high penetration of EVs.

\subsubsection{Robust optimization}

Robust optimization is an effective method to solve the optimization problems with uncertainties, especially in the case that the information of uncertainties are not fully available. The main idea of robust optimization is to find the optimal solution in the worst case. Zhou et al. [181] proposed a day-ahead scheduling method for the integrated community energy systems in joint energy and ancillary service markets. The uncertainties, including prices of energy market, prices of ancillary service market, wind power, and solar power, were considered by using the robust optimization approach. An optimal bidding method for a microgrid in day-ahead energy market was proposed in [182], in which a hybrid stochastic and robust optimization model was developed to minimize the expected operational cost of the microgrid. A distributed robust optimization method for multiple interconnected microgrids was developed in [183]. The total operational cost of the microgrids was reduced through local energy trading with neighboring microgrids in the real-time LEM.

Table 10 summarizes the formulations and solution approaches related to LFMs and LEMs.

Table 10

\begin{tabular}{|c|c|c|c|c|c|c|c|c|c|}
\hline \multirow[b]{2}{*}{ Ref. } & \multicolumn{4}{|c|}{ Models } & \multicolumn{4}{|c|}{ Solution approach } & \multirow[b]{2}{*}{$\begin{array}{l}\text { Mark } \\
\text { et }\end{array}$} \\
\hline & $\begin{array}{c}\text { Centralize } \\
\mathrm{d} \\
\text { optimizati } \\
\text { on models }\end{array}$ & $\begin{array}{c}\text { Game } \\
\text { theory- } \\
\text { based } \\
\text { models }\end{array}$ & $\begin{array}{c}\text { Aucti } \\
\text { on } \\
\text { theory } \\
\text {-based } \\
\text { model } \\
\text { s }\end{array}$ & $\begin{array}{c}\text { Simulati } \\
\text { on } \\
\text { models }\end{array}$ & $\begin{array}{c}\text { Centralize } \\
d \\
\text { optimizati } \\
\text { on }\end{array}$ & $\begin{array}{l}\text { Decomposit } \\
\text { ion methods }\end{array}$ & $\begin{array}{c}\text { Multi- } \\
\text { level } \\
\text { optimizati } \\
\text { on }\end{array}$ & $\begin{array}{l}\text { Optimizati } \\
\text { on with } \\
\text { uncertainti } \\
\text { es }\end{array}$ & \\
\hline$[8]$ & & $\begin{array}{c}\sqrt{ } \\
\text { (Noncoop } \\
\text { erative } \\
\text { game) }\end{array}$ & & & $\sqrt{ }(\mathrm{MILP})$ & & & & LEM \\
\hline$[10]$ & & $\begin{array}{c}\sqrt{ } \\
\text { (Noncoop }\end{array}$ & & & $\sqrt{ }($ MILP) & & & & LEM \\
\hline
\end{tabular}


erative

game)

[11] V

[21],

[64],

[72],

[73],

[79]-

[81]

[33]

[47]

[78]

[120],

[121]

[125]

[152]

[178]

$\checkmark$

$\sqrt{ }$

$\sqrt{ }$

$\sqrt{ }$

$\sqrt{ }$

erative game)

$\sqrt{ }$

erative

game)

$\checkmark$

game)

$\checkmark$
(Noncoop

(Noncoop

$\sqrt{ }(\mathrm{GA})$

$\sqrt{ }$ (MILP)

(MINLP)

$\sqrt{ }$ (MILP)

LFM

LFM

LEM

$\sqrt{ }$ (Bi-level

optimizati

on)

$\sqrt{ }$ (MILP)

LEM

$\sqrt{ }$ (Bi-level

optimizati

on)

$\checkmark$ (Dual

decompositi

on)

$\sqrt{ }$ (MILP

for each

agent)

$\checkmark$ (SOCP)

$\sqrt{ }(\mathrm{QP})$

(Noncoop

LFM

LEM

LEM

LEM

LEM

LEM

$\sqrt{ }$ (Dual

decompositi

on)

$\sqrt{ }$ (Bi-level
optimizati
on)

LEM

LEM

$\sqrt{ }$

(Stochasti

c LEM

programm ing)

\section{Future research directions}

According to the discussion in this paper, we point out possibilities of technologies and research as follows:

(1) Considering the physical electric network in LFMs design and clearing

Players in LFMs use electric network to delivery energy and flexibility services. However, some existing approaches for LFMs design and clearing omit the physical electric network, the electric power flow and the corresponding operational constraints (e.g. voltage limits). Consequently, large number of players trading flexibility utilizing electric network as physical carriers may lead to unreasonable clearing results. Hence, the physical electric network, the electric power flow and the corresponding operational 
constraints of the distribution systems are suggested to be taken into account in LFMs design and clearing.

(2) Involving flexibility from other energy vectors in LFM design

The flexibility trading in LFMs in current published studies is mainly from the electricity vector. The multi-energy systems offer great opportunities for the electric systems to get cost effective flexibility by capitalizing on synergies and complementary advantages of the various energy systems at various scales. Therefore, flexibility from other energy vectors is recommended to be considered in the designs of LFMs.

(3) Using comprehensive methods to solve operational problems for DSOs

As introduced in Section 3, both the market-based methods and control-based methods can solve operational problems for DSOs. Therefore, DSOs can use comprehensive methods by integrating these methods together to solve their operational problems. Cost benefits can be obtained by the DSOs through optimal coordination among these methods, which would be suggested as one of the future research directions. Furthermore, other operational problems for distribution systems (e.g., voltage control, load balancing, loss reduction, etc.) should also be studied apart from congestion management in the future

(4) Conducting experimental investigations and demonstrations of LFMs

Current research works are mainly focus on the level of simulations and algorithms. Additional experimental investigations and demonstrations for LFMs' applications in the real-world markets are also needed.

\section{Conclusions}

With the high penetrations of renewable generations and DERs, the distribution networks are facing new operational challenges due to their intermittent characteristic and increased network utilization. LFMs can provide opportunities for DSO to cope with these challenges, which are widely discussed in the literature. Studies have been carried out to define the concept, design the mechanism and formulate the market clearing methods of LFMs in the literature. Therefore, this paper reviewed the published papers on this topic to provide a clear understanding of the concepts, formulations and clearing methods of LFMs in the literature. Starting with a survey on the concepts and definitions of LFMs, we summarize the key elements, technologies and participants of LFMs. Then, the reviewed papers are classified based on market models and clearing methods. The formulations and clearing methods are reviewed and compared. Furthermore, studies for solving operational issues of the distribution systems due to high penetration of DERs were also reviewed to highlight the importance of LFMs in this paper. It is expected that this study can provide a comprehensive survey in LFMs and encourage more and more studies in this field. 


\section{Acknowledgements}

This work was financially supported by the transnational project "Multi-layer aggregator solutions to facilitate optimum demand response and grid flexibility" (SMART-MLA Project No: 89029), cofinanced by TÜBİTAK (Turkey), SWEA (Sweden), EUDP (Denmark), UEFISCDI (Romania), and RCN (Norway) under ERA-Net Smart Energy Systems SG+ 2017 Program.

\section{Reference}

[1] Ramos A, De Jonghe C, Gómez V, Belmans R. Realizing the smart grid's potential: Defining local markets for flexibility. Util Policy 2016;40:26-35. doi:10.1016/j.jup.2016.03.006.

[2] Ma W, Xue X, Liu G. Techno-economic evaluation for hybrid renewable energy system: Application and merits. Energy 2018;159:385-409. doi:10.1016/j.energy.2018.06.101.

[3] Hamilton J, Negnevitsky M, Wang X, Lyden S. High penetration renewable generation within Australian isolated and remote power systems. Energy 2019;168:684-92. doi:10.1016/j.energy.2018.11.118.

[4] European Commission. Climate action - 2020 climate \& energy package. Online information: $<$ https://ec.europa.eu/clima/policies/strategies/2020_en>

[5] European Commission. Climate action - 2030 climate \& energy framework. Online information:< $\underline{\text { https://ec.europa.eu/clima/policies/strategies/2030 en> }}$

[6] The Danish Government. The Danish Climate Policy Plan: towards a low carbon society; 2013.

[7] The Press and Information Office of the Federal Government. Switching to the electricity of the future. Arch Der Bundesregierung; 2011. 1. http://archiv.bundesregierung.de/ContentArchiv/EN/Archiv17/Arti kel/_2011/06/2011-06-09-regierungserklaerung_en.html.

[8] Zhou Y, Wu J, Long C. Evaluation of peer-to-peer energy sharing mechanisms based on a multiagent simulation framework. Appl Energy 2018;222:993-1022. doi:10.1016/j.apenergy.2018.02.089.

[9] Eid, C., Codani, P., Perez, Y., Reneses, J., \& Hakvoort, R. (2016). Managing electric flexibility from Distributed Energy Resources: A review of incentives for market design. Renewable and Sustainable Energy Reviews, 64, 237-247. https://doi.org/10.1016/j.rser.2016.06.008

[10] Zhang C, Wu J, Zhou Y, Cheng M, Long C. Peer-to-Peer energy trading in a Microgrid. Appl Energy 2018;220:1-12. doi:10.1016/j.apenergy.2018.03.010. 
[11] Long C, Wu J, Zhou Y, Jenkins N. Peer-to-peer energy sharing through a two-stage aggregated battery control in a community Microgrid. Appl Energy 2018;226:261-76. doi:10.1016/j.apenergy.2018.05.097.

[12] Khorasany M, Mishra Y, Ledwich G. Market framework for local energy trading: a review of potential designs and market clearing approaches. IET Gener Transm Distrib 2018;12:5899-908. doi:10.1049/iet$\operatorname{gtd} .2018 .5309$.

[13] Jin X, Jiang T, Mu Y, Long C, Li X, Jia H, et al. Scheduling distributed energy resources and smart buildings of a microgrid via multi-time scale and model predictive control method. IET Renew Power Gener 2019;13:816-33. doi:10.1049/iet-rpg.2018.5567.

[14] Jiang T, Li Z, Jin X, Chen H, Li X, Mu Y. Flexible operation of active distribution network using integrated smart buildings with heating, ventilation and air-conditioning systems. Appl Energy 2018;226:181-96. doi:10.1016/j.apenergy.2018.05.091.

[15] International Energy Agency, World Energy Outlook 2017: A world in transformation, http://www.iea.org/weo2017, accessed 14 November 2017.

[16] Golshannavaz S, Afsharnia S, Aminifar F. Smart distribution grid: Optimal day-ahead scheduling with reconfigurable topology. IEEE Trans Smart Grid 2014;5:2402-11. doi:10.1109/TSG.2014.2335815.

[17] Garcia ED, Pereira PR, Canha LN, Popov VA. Grid functional blocks methodology to dynamic operation and decision making in Smart Grids. Int J Electr Power Energy Syst 2018;103:267-76. doi:10.1016/j.ijepes.2018.06.002.

[18] Faruqui A, Harris D, Hledik R. Unlocking the $€ 53$ billion savings from smart meters in the EU: how increasing the adoption of dynamic tariffs could make or break the EU's smart grid investment. Energy Policy 2010;38:6222-31.

[19] Lin C-C, Yang C-H, Shyua JZ. A comparison of innovation policy in the smart grid industry across the pacific: China and the USA. Energy Policy 2013:1-14. http://dx.doi.org/10.1016/j.enpol.2012.12.028.

[20] Haidar AMA, Muttaqi K, Sutanto D. Smart Grid and its future perspectives in Australia. Renew Sustain Energy Rev 2015;51:1375-89. http://dx.doi.org/ 10.1016/j.rser.2015.07.040.

[21] Olivella-Rosell, P., Bullich-Massagué, E., Aragüés-Peñalba, M., Sumper, A., Ottesen, S. Ø., Vidal-Clos, J. A., \& Villafáfila-Robles, R. (2018). Optimization problem for meeting distribution system operator 
requests in local flexibility markets with distributed energy resources. Applied Energy, 210(September 2017), 881-895. https://doi.org/10.1016/j.apenergy.2017.08.136

[22] Ottesen SO, Tomasgard A. A stochastic model for scheduling energy flexibility in buildings. Energy 2015;88:364-76. doi:10.1016/j.energy.2015.05.049.

[23] Junker RG, Azar AG, Lopes RA, Lindberg KB, Reynders G, Relan R, et al. Characterizing the energy flexibility of buildings and districts. Appl Energy 2018;225:175-82. doi:10.1016/j.apenergy.2018.05.037.

[24] Denmark: Danish Energy Agency. Overview map of the Danish power infrastructure in 1985 and 2018. https://ens.dk/en/ourservices/statistics-data-key-figures-and-energy-maps/energy-infomaps.

[25] Huang S, Wu Q, Cheng L, Liu Z, Zhao H. Uncertainty Management of Dynamic Tariff Method for Congestion Management in Distribution Networks. IEEE Trans Power Syst 2016;31:4340-7. doi:10.1109/TPWRS.2016.2517645.

[26] Wu J, Yan J, Jia H, Hatziargyriou N, Djilali N, Sun H. Integrated Energy Systems. Appl Energy 2016;167:155-7. doi:10.1016/j.apenergy.2016.02.075.

[27] Jin X, Mu Y, Jia H, Wu J, Xu X, Yu X. Optimal day-ahead scheduling of integrated urban energy systems. Appl Energy 2016;180:1-13. doi:10.1016/j.apenergy.2016.07.071.

[28] Hong B, Chen J, Zhang W, Shi Z, Li J, Miao W. Integrated energy system planning at modular regionaluser level based on a two-layer bus structure. CSEE J Power Energy Syst 2018;4:188-96. doi:10.17775/cseejpes.2018.00110.

[29] Lei Y, Hou K, Wang Y, Jia H, Zhang P, Mu Y, et al. A new reliability assessment approach for integrated energy systems: Using hierarchical decoupling optimization framework and impact-increment based state enumeration method. Appl Energy 2017;210:1237-50. doi:10.1016/j.apenergy.2017.08.099.

[30] Hu J, Yang G, Bindner HW, Xue Y. Application of Network-Constrained Transactive Control to Electric Vehicle Charging for Secure Grid Operation. IEEE Trans Sustain Energy 2017;8:505-15. doi:10.1109/TSTE.2016.2608840.

[31] Thomas L, Zhou Y, Long C, Wu J, Jenkins N. A general form of smart contract for decentralized energy systems management. Nat Energy 2019;4. doi:10.1038/s41560-018-0317-7.

[32] De Jong J, Hassel A, Jansen J, et al. Improving the market for flexibility in the electricity sector[R]. Centre for European Policy Studies, 2017. 
[33] Esmat A, Usaola J, Moreno MÁ. Distribution-level flexibility market for congestion management. Energies 2018;11. doi:10.3390/en11051056.

[34] Villar J, Bessa R, Matos M. Flexibility products and markets: Literature review. Electr Power Syst Res 2018;154:329-40. doi:10.1016/j.epsr.2017.09.005.

[35] Weber C. Adequate intraday market design to enable the integration of wind energy into the European power systems. Energy Policy 2010;38:3155-63. doi:10.1016/j.enpol.2009.07.040.

[36] Padmanabhan N, Ahmed M, Bhattacharya K. Simultaneous Procurement of Demand Response Provisions in Energy and Spinning Reserve Markets. IEEE Trans Power Syst 2018;33:4667-82. doi:10.1109/TPWRS.2018.2806879.

[37] Jin X, Mu Y, Jia H, Wu Q, Jiang T, Wang M, et al. Alleviation of overloads in transmission network : A multi-level framework using the capability from active distribution network. Int J Electr Power Energy Syst 2019;112:232-51. doi:10.1016/j.ijepes.2019.05.007.

[38] Roos A. Designing a joint market for procurement of transmission and distribution system services from demand flexibility. Renew Energy Focus 2017;21:16-24. doi:10.1016/j.ref.2017.06.004.

[39] EURELECTRIC, Flexibility and Aggregation Requirements for their interaction in the market (2014).

[40] R. Belhomme, M. Sebastian, "Deliverable 1.1 ADDRESS - Technical and commercial conceptual architectures," Oct. 2009. $\quad$ http://www.addressfp7.org/config/files/ADD-WP1_Technical_andCommercial_Architectures.pdf.

[41] Strategic Platform for Innovation and Research in Intelligent Power, https://ipower-net.weebly.com/

[42] Brandherm B, Baus J, Frey J. Peer energy cloud-Civil marketplace for trading renewable energies. Proc - 8th Int Conf Intell Environ IE 2012 2012:375-8. doi:10.1109/IE.2012.46.

[43] Gantenbein D, Binding C, Jansen B, et al. EcoGrid EU: An efficient ICT approach for a sustainable power system[C]//2012 Sustainable Internet and ICT for Sustainability (SustainIT). IEEE, 2012: 1-6.

[44] Open Utility. A Glimpes into the Future of Britain's Energy Economy. https://piclo.uk.

[45] Local Electricity Retail Markets for Prosumer Smart Grid Power Services, www.empowerh2020.eu.

[46] Zhang Y, Campana PE, Yang Y, Stridh B, Lundblad A, Yan J. Energy flexibility from the consumer: Integrating local electricity and heat supplies in a building. Appl Energy 2018;223:430-42. doi:10.1016/j.apenergy.2018.04.041. 
[47] Rahbari-Asr N, Ojha U, Zhang Z, Chow MY. Incremental welfare consensus algorithm for cooperative distributed generation/demand response in smart grid. IEEE Trans Smart Grid 2014;5:2836-45. doi:10.1109/TSG.2014.2346511.

[48] Wu D, Yang T, Stoorvogel AA, Stoustrup J. Distributed Optimal Coordination for Distributed Energy Resources in Power Systems. IEEE Trans Autom Sci Eng 2017;14:414-24. doi:10.1109/TASE.2016.2627006.

[49] Wang Y, Tan KT, Peng XY, So PL. Coordinated Control of Distributed Energy-Storage Systems for Voltage Regulation in Distribution Networks. IEEE Trans Power Deliv 2016;31:1132-41. doi:10.1109/TPWRD.2015.2462723.

[50] Hafez O, Bhattacharya K. Optimal design of electric vehicle charging stations considering various energy resources. Renew Energy 2017;107:576-89. doi:10.1016/j.renene.2017.01.066.

[51] Sun Q, Han R, Zhang H, Zhou J, Guerrero JM. A Multiagent-Based Consensus Algorithm for Distributed Coordinated Control of Distributed Generators in the Energy Internet. IEEE Trans Smart Grid 2015;6:3006-19. doi:10.1109/TSG.2015.2412779.

[52] Yuan Z, Hesamzadeh MR. Hierarchical coordination of TSO-DSO economic dispatch considering largescale integration of distributed energy resources. Appl Energy 2017;195:600-15. doi:10.1016/j.apenergy.2017.03.042.

[53] Gerard H, Rivero Puente EI, Six D. Coordination between transmission and distribution system operators in the electricity sector: A conceptual framework. Util Policy 2018;50:40-8. doi:10.1016/j.jup.2017.09.011.

[54] Li Z, Guo Q, Sun H, Wang J. Coordinated economic dispatch of coupled transmission and distribution systems using heterogeneous decomposition. IEEE Trans Power Syst 2016;31:4817-30. doi:10.1109/TPWRS.2016.2515578.

[55] Palensky P, Dietrich D. Demand side management: Demand response, intelligent energy systems, and smart loads. IEEE Trans Ind Informatics 2011;7:381-8. doi:10.1109/TII.2011.2158841.

[56] Henriquez R, Wenzel G, Olivares DE, Negrete-Pincetic M. Participation of demand response aggregators in electricity markets: Optimal portfolio management. IEEE Trans Smart Grid 2018;9:4861-71. doi:10.1109/TSG.2017.2673783. 
[57] Conte F, Massucco S, Silvestro F. Frequency control services by a building cooling system aggregate. Electr Power Syst Res 2016;141:137-46. doi:10.1016/j.epsr.2016.07.003.

[58] Zhao H, Wu Q, Huang S, Zhang H, Liu Y, Xue Y. Hierarchical Control of Thermostatically Controlled Loads for Primary Frequency Support. IEEE Trans Smart Grid 2018;9:2986-98. doi:10.1109/TSG.2016.2624509.

[59] Hanif S, Massier T, Gooi HB, Hamacher T, Reindl T. Cost Optimal Integration of Flexible Buildings in Congested Distribution Grids. IEEE Trans Power Syst 2017;32:2254-66. doi:10.1109/TPWRS.2016.2605921.

[60] Jin X, Mu Y, Jia H, Wu J, Jiang T, Yu X. Dynamic economic dispatch of a hybrid energy microgrid considering building based virtual energy storage system. Appl Energy 2017;194:386-98. doi:10.1016/j.apenergy.2016.07.080.

[61] Jin X, Wu J, Mu Y, Wang M, Xu X, Jia H. Hierarchical microgrid energy management in an office building. Appl Energy 2017;208:480-94. doi:10.1016/j.apenergy.2017.10.002.

[62] O’Connell N, Wu Q, Østergaard J, Nielsen AH, Cha ST, Ding Y. Day-ahead tariffs for the alleviation of distribution grid congestion from electric vehicles. Electr Power Syst Res 2012;92:106-14. doi:10.1016/j.epsr.2012.05.018.

[63] Liu Z, Wu Q, Shahidehpour M, Li C, Huang S, Wei W. Transactive Real-time Electric Vehicle Charging Management for Commercial Buildings with PV On-site Generation. IEEE Trans Smart Grid 2018;PP:1. doi:10.1109/TSG.2018.2871171.

[64] Spiliotis K, Ramos Gutierrez AI, Belmans R. Demand flexibility versus physical network expansions in distribution grids. Appl Energy 2016;182:613-24. doi:10.1016/j.apenergy.2016.08.145.

[65] Roos, J. G., \& Lane, I. E. (2002). Industrial power demand response analysis for one-part real-time pricing. IEEE Transactions on Power Systems, 13(1), 159-164. https://doi.org/10.1109/59.651628

[66] Ding, Y. M., Hong, S. H., \& Li, X. H. (2014). A demand response energy management scheme for industrial facilities in smart grid. IEEE Transactions on Industrial Informatics, 10(4), 2257-2269. https://doi.org/10.1109/TII.2014.2330995 
[67] Shoreh, M. H., Siano, P., Shafie-khah, M., Loia, V., \& Catalão, J. P. S. (2016). A survey of industrial applications of Demand Response. Electric Power Systems Research, 141, 31-49. https://doi.org/10.1016/j.epsr.2016.07.008

[68] Long C, Ochoa LF. Voltage control of PV-rich LV networks: OLTC-fitted transformer and capacitor banks. IEEE Trans Power Syst 2016;31:4016-25. doi:10.1109/TPWRS.2015.2494627.

[69] Mehmood KK, Khan SU, Lee SJ, Haider ZM, Rafique MK, Kim CH. A real-time optimal coordination scheme for the voltage regulation of a distribution network including an OLTC, capacitor banks, and multiple distributed energy resources. Int J Electr Power Energy Syst 2018;94:1-14. doi:10.1016/j.ijepes.2017.06.024.

[70] Chen L, Li HY, Cox S, Bailey K. Ancillary Service for Transmission Systems by Tap Stagger Operation in Distribution Networks. IEEE Trans Power Deliv 2016;31:1701-9. doi:10.1109/TPWRD.2015.2504599.

[71] Qi Q, Wu J, Long C. Multi-objective operation optimization of an electrical distribution network with soft open point. Appl Energy 2017;208:734-44. doi:10.1016/j.apenergy.2017.09.075.

[72] Torbaghan SS, Blaauwbroek N, Kuiken D, Gibescu M, Hajighasemi M, Nguyen P, et al. A market-based framework for demand side flexibility scheduling and dispatching. Sustain Energy, Grids Networks 2018;14:47-61. doi:10.1016/j.segan.2018.03.003.

[73] Olivella-Rosell P, Lloret-Gallego P, Munné-Collado Í, et al. Local Flexibility Market Design for Aggregators Providing Multiple Flexibility Services at Distribution Network Level. Energies 2018;11:822. doi:10.3390/en11040822.

[74] Cheng M, Wu J, Galsworthy SJ, Ugalde-Loo CE, Gargov N, Hung WW, et al. Power system frequency response from the control of bitumen tanks. IEEE Trans Power Syst 2016;31:1769-78. doi:10.1109/TPWRS.2015.2440336.

[75] Balance Responsible Parties (BRPs) (2014). https://www.emissions-euets.com/-balance-responsible-parties$\underline{\text { brp }}$

[76] Burger S, Chaves-Ávila JP, Batlle C, Pérez-Arriaga IJ. A review of the value of aggregators in electricity systems. Renew Sustain Energy Rev 2017;77:395-405. doi:10.1016/j.rser.2017.04.014.

[77] Morstyn T, Teytelboym A, McCulloch MD. Designing decentralized markets for distribution system flexibility. IEEE Trans Power Syst 2019;34:1-12. doi:10.1109/TPWRS.2018.2886244. 
[78] Torbaghan SS, Blaauwbroek N, Nguyen P, Gibescu M. Local market framework for exploiting flexibility from the end users. Int Conf Eur Energy Mark EEM 2016;2016-July:1-6. doi:10.1109/EEM.2016.7521304.

[79] Heussen K, Bondy DEM, Hu J, Gehrke O, Hansen LH. A clearinghouse concept for distribution-level flexibility services. 2013 4th IEEE/PES Innov Smart Grid Technol Eur ISGT Eur 2013 2013:1-5. doi:10.1109/ISGTEurope.2013.6695483.

[80] Zhang C, Ding Y, Østergaard J, Bindner HW, Nordentoft NC, Hansen LH, et al. A flex-market design for flexibility services through DERs. 2013 4th IEEE/PES Innov Smart Grid Technol Eur ISGT Eur 2013 2013:15. doi:10.1109/ISGTEurope.2013.6695286.

[81] ZHANG C, DING Y, NORDENTOFT NC, PINSON P, ØSTERGAARD J. FLECH: A Danish market solution for DSO congestion management through DER flexibility services. J Mod Power Syst Clean Energy 2014;2:126-33. doi:10.1007/s40565-014-0048-0.

[82] De Jong J, Hassel A, Jansen J, et al. Improving the market for flexibility in the electricity sector[R]. Centre for European Policy Studies, 2017.

[83] Bertsch V, Hall M, Weinhardt C, Fichtner W. Public acceptance and preferences related to renewable energy and grid expansion policy: Empirical insights for Germany. Energy 2016;114:465-77. doi:10.1016/j.energy.2016.08.022.

[84] Van Der Schoor T, Scholtens B. Power to the people: Local community initiatives and the transition to sustainable energy. Renew Sustain Energy Rev 2015;43:666-75. doi:10.1016/j.rser.2014.10.089.

[85] Morstyn T, Farrell N, Darby SJ, McCulloch MD. Using peer-to-peer energy-trading platforms to incentivize prosumers to form federated power plants. Nat Energy 2018;3:94-101. doi:10.1038/s41560-017-0075-y.

[86] Park S, Lee J, Bae S, Hwang G, Choi JK. Contribution-Based Energy-Trading Mechanism in Microgrids for Future Smart Grid: A Game Theoretic Approach. IEEE Trans Ind Electron 2016;63:4255-65. doi:10.1109/TIE.2016.2532842.

[87] Liu T, Tan X, Sun B, Wu Y, Guan X, Tsang DHK. Energy management of cooperative microgrids with P2P energy sharing in distribution networks. 2015 IEEE Int Conf Smart Grid Commun SmartGridComm 2015 2016:410-5. doi:10.1109/SmartGridComm.2015.7436335.

[88] Pudjianto D, Ramsay C, Strbac G. Virtual power plant and system integration of distributed energy resources. IET Renew Power Gener 2007;1(1):10. http://dx.doi. org/10.1049/iet-rpg:20060023. 
[89] Ghiani E, Pilo F, Celli G. Definition of Smart Distribution Networks. Elsevier Inc.; 2018. doi:10.1016/b9780-12-814891-4.00001-1.

[90] Ruiz N, Cobelo I, Oyarzabal J. A direct load control model for virtual power plant management. IEEE Trans Power Syst 2009;24(2):959-66. http://dx.doi.org/10. 1109/TPWRS.2009.2016607.

[91] Pandžić H, Morales JM, Conejo AJ, Kuzle I. Offering model for a virtual power plant based on stochastic programming. Appl Energy 2013;105:282-92. http://dx.doi. org/10.1016/j.apenergy.2012.12.077.

[92] Pandžić H, Kuzle I, Capuder T. Virtual power plant mid-term dispatch optimization. Appl Energy 2013;101:134-41. http://dx.doi.org/10.1016/j.apenergy.2012.05. 039.

[93] Peik-Herfeh M, Seifi H, Sheikh-El-Eslami M. Decision making of a virtual power plant under uncertainties for bidding in a day-ahead market using point estimate method. Int J Electric Power Energy Syst 2013;44(1):88-98. http://dx.doi.org/10. 1016/j.ijepes.2012.07.016.

[94] Giuntoli M, Poli D. Optimized thermal and electrical scheduling of a large scale virtual power plant in the presence of energy storages. IEEE Trans Smart Grid 2013;4(2):942-55. http://dx.doi.org/10.1109/TSG.2012.2227513.

[95] Hu Z, Li F. Cost-benefit analyses of active distribution network management, part I: Annual benefit analysis. IEEE Trans Smart Grid 2012;3:1067-74. doi:10.1109/TSG.2012.2205412.

[96] Sundström O, Binding C. Flexible charging optimization for electric vehicles considering distribution grid constraints. IEEE Trans Smart Grid 2012;3:26-37. doi:10.1109/TSG.2011.2168431.

[97] Van Halewyck L, Verstraeten J, Strobbe M, Develder C. Economic evaluation of active network management alternatives for congestion avoidance - The DSO perspective. IEEE PES Innov Smart Grid Technol Conf Eur 2015;2015-Janua:1-6. doi:10.1109/ISGTEurope.2014.7028941.

[98] Koutsoukis NC, Siagkas DiO, Georgilakis PS, Hatziargyriou ND. Online Reconfiguration of Active Distribution Networks for Maximum Integration of Distributed Generation. IEEE Trans Autom Sci Eng 2017;14:437-48. doi:10.1109/TASE.2016.2628091.

[99] Long C, Wu J, Thomas L, Jenkins N. Optimal operation of soft open points in medium voltage electrical distribution networks with distributed generation. Appl Energy 2016;184:427-37. doi:10.1016/j.apenergy.2016.10.031.

[100] Li P, Ji H, Zhao J, Wang C, Ding F, Wu J, et al. Coordinated Control Method of Voltage and Reactive 
Power for Active Distribution Networks Based on Soft Open Point. IEEE Trans Sustain Energy 2017;8:143042. doi:10.1109/tste.2017.2686009.

[101] Li P, Ji H, Yu H, Zhao J, Wang C, Song G, et al. Combined decentralized and local voltage control strategy of soft open points in active distribution networks. Appl Energy 2019;241:613-24. doi:10.1016/j.apenergy.2019.03.031.

[102] Sotkiewicz P M, Vignolo J M. Nodal pricing for distribution networks: efficient pricing for efficiency enhancing DG. IEEE transactions on power systems, 2006, 21(2): 1013-1014.

[103] Heydt GT, Chowdhury BH, Crow ML, Haughton D, Kiefer BD, Meng F, et al. Pricing and control in the next generation power distribution system. IEEE Trans Smart Grid 2012;3:907-14. doi:10.1109/TSG.2012.2192298.

[104] Li R, Wu Q, Oren SS. Distribution locational marginal pricing for optimal electric vehicle charging management. IEEE Trans Power Syst 2014;29:203-11. doi:10.1109/TPWRS.2013.2278952.

[105] Huang S, Wu Q, Oren SS, Li R, Liu Z. Distribution Locational Marginal Pricing Through Quadratic Programming for Congestion Management in Distribution Networks. IEEE Trans Power Syst 2015;30:2170_ 8. doi:10.1109/TPWRS.2014.2359977.

[106] Huang S, Wu Q, Cheng L, Liu Z. Optimal Reconfiguration-Based Dynamic Tariff for Congestion Management and Line Loss Reduction in Distribution Networks. IEEE Trans Smart Grid 2016;7:1295-303. doi:10.1109/TSG.2015.2419080.

[107] Huang S, Wu Q, Zhao H, Li C. Distributed Optimization-Based Dynamic Tariff for Congestion Management in Distribution Networks. IEEE Trans Smart Grid 2019;10:184-92. doi:10.1109/TSG.2017.2735998.

[108] Shen F, Wu Q, Huang S. Day-Ahead Congestion Management Scheme for Distribution Networks with Dynamic Tariff and Re-profiling Products. Int $J$ Smart Grid Clean Energy. in press. http://orbit.dtu.dk/files/158504313/E0008_Day_ahead_congestion_management_scheme_for_distribution_n etworks_with_dynamic_tariff_and_re_profiling_products.pdf.

[109] Shen F, Huang S, Wu Q, et al. Comprehensive Congestion Management for Distribution Networks based on Dynamic Tariff, Reconfiguration and Re-profiling Product. IEEE Transactions on Smart Grid, in press. http://orbit.dtu.dk/files/152806203/Comprehensive_Congestion_Management_for_Distribution_Networks.p 
df.

[110] The GridWise Architecture Council, GridWise Transactive Energy Framework Version 1.0, Tech. rep.; 2015. http://www.gridwiseac.org/pdfs/te_framework_report_pnnl-22946.pdf.

[111] Hu J, Yang G, Kok K, Xue Y, Bindner HW. Transactive control: a framework for operating power systems characterized by high penetration of distributed energy resources. J Mod Power Syst Clean Energy 2017;5:451-64. doi:10.1007/s40565-016-0228-1.

[112] Hu J, Yang G, Xue Y. Economic assessment of network-constrained transactive energy for managing flexible demand in distribution systems. Energies 2017;10. doi:10.3390/en10050711.

[113] Marzband M, Azarinejadian F, Savaghebi M, Pouresmaeil E, Guerrero JM, Lightbody G. Smart transactive energy framework in grid-connected multiple home microgrids under independent and coalition operations. Renew Energy 2018;126:95-106. doi:10.1016/j.renene.2018.03.021.

[114] Liu Y, Gooi HB, Li Y, Xin H, Ye J. A Secure Distributed Transactive Energy Management Scheme for Multiple Interconnected Microgrids Considering Misbehaviors. IEEE Trans Smart Grid 2019;PP:1-1. doi:10.1109/TSG.2019.2895229.

[115] European Commission. Proposal for a Directive of the European Parliament and of the Council on common rules for the internal market in electricity, Tech. rep.; 2016.

[116] Parhizi S, Khodaei A, Shahidehpour M. Market-based versus price-based microgrid optimal scheduling. IEEE Trans Smart Grid 2018;9:615-23. doi:10.1109/TSG.2016.2558517.

[117] Tushar W, Yuen C, Mohsenian-Rad H, Saha T, Poor HV, Wood KL. Transforming energy networks via peer-to-peer energy trading: The potential of game-theoretic approaches. IEEE Signal Process Mag 2018;35:90-111. doi:10.1109/MSP.2018.2818327.a

[118] Paudel A, Chaudhari K, Long C, Gooi HB. Peer-to-peer energy trading in a prosumer-based community microgrid: A game-theoretic model. IEEE Trans Ind Electron 2019;66:6087-97. doi:10.1109/TIE.2018.2874578.

[119] Morstyn T, Teytelboym A, McCulloch MD. Bilateral contract networks for peer-to-peer energy trading. IEEE Trans Smart Grid 2019;10:2026-35. doi:10.1109/TSG.2017.2786668.

[120] Su W, Huang AQ. A game theoretic framework for a next-generation retail electricity market with high penetration of distributed residential electricity suppliers. Appl Energy 2014;119:341-50. 
doi:10.1016/j.apenergy.2014.01.003.

[121] Marzband M, Javadi M, Pourmousavi SA, Lightbody G. An advanced retail electricity market for active distribution systems and home microgrid interoperability based on game theory. Electr Power Syst Res 2018;157:187-99. doi:10.1016/j.epsr.2017.12.024.

[122] Lee J, Guo J, Choi JK, Zukerman M. Distributed energy trading in microgrids: A game-theoretic model and its equilibrium analysis. IEEE Trans Ind Electron 2015;62:3524-33. doi:10.1109/TIE.2014.2387340.

[123] Wei F, Jing ZX, Wu PZ, Wu QH. A Stackelberg game approach for multiple energies trading in integrated energy systems. Appl Energy 2017;200:315-29. doi:10.1016/j.apenergy.2017.05.001.

[124] Jia L, Tong L. Dynamic Pricing and Distributed Energy Management for Demand Response. IEEE Trans Smart Grid 2016;7:1128-36. doi:10.1109/TSG.2016.2515641.

[125] Liu N, Yu X, Wang C, Wang J. Energy Sharing Management for Microgrids with PV Prosumers: A Stackelberg Game Approach. IEEE Trans Ind Informatics 2017;13:1088-98. doi:10.1109/TII.2017.2654302.

[126] Zhou Z, Xiong F, Huang B, Xu C, Jiao R, Liao B, et al. Game-Theoretical Energy Management for Energy Internet with Big Data-Based Renewable Power Forecasting. IEEE Access 2017;5:5731-46. doi:10.1109/ACCESS.2017.2658952.

[127] Ma K, Hu G, Spanos CJ. A cooperative demand response scheme using punishment mechanism and application to industrial refrigerated warehouses. IEEE Trans Ind Informatics 2015;11:1520-31. doi:10.1109/TII.2015.2431219.

[128] Han L, Morstyn T, McCulloch M. Incentivizing Prosumer Coalitions With Energy Management Using Cooperative Game Theory. IEEE Trans Power Syst 2019;34:303-13. doi:10.1109/TPWRS.2018.2858540.

[129] Lee W, Xiang L, Schober R, Wong VWS. Direct electricity trading in smart grid: A coalitional game analysis. IEEE J Sel Areas Commun 2014;32:1398-411. doi:10.1109/JSAC.2014.2332112.

[130] Fanzeres B, Ahmed S, Street A. Robust strategic bidding in auction-based markets. Eur J Oper Res 2019;272:1158-72. doi:10.1016/j.ejor.2018.07.027.

[131] Zaidi BH, Hong SH. Combinatorial double auctions for multiple microgrid trading. Electr Eng 2018;100:1069-83. doi:10.1007/s00202-017-0570-y.

[132] Zhong W, Xie K, Liu Y, Yang C, Xie S. Auction Mechanisms for Energy Trading in Multi-Energy Systems. IEEE Trans Ind Informatics 2018;14:1511-21. doi:10.1109/TII.2017.2787751. 
[133] Kang J, Yu R, Huang X, Maharjan S, Zhang Y, Hossain E. Enabling Localized Peer-to-Peer Electricity Trading among Plug-in Hybrid Electric Vehicles Using Consortium Blockchains. IEEE Trans Ind Informatics 2017;13:3154-64. doi:10.1109/TII.2017.2709784.

[134] Park L, Jeong S, Kim J, Cho S. Joint Geometric Unsupervised Learning and Truthful Auction for Local Energy Market. IEEE Trans Ind Electron 2019;66:1499-508. doi:10.1109/TIE.2018.2849979.

[135] Ringler P, Keles D, Fichtner W. Agent-based modelling and simulation of smart electricity grids and markets - A literature review. Renew Sustain Energy Rev 2016;57:205-15. doi:10.1016/j.rser.2015.12.169.

[136] Coelho VN, Weiss Cohen M, Coelho IM, Liu N, Guimarães FG. Multi-agent systems applied for energy systems integration: State-of-the-art applications and trends in microgrids. Appl Energy 2017;187:820-32. doi:10.1016/j.apenergy.2016.10.056.

[137] Wooldridge M. Intelligent agents. Multiagent systems, Cambridge, MA: MIT Press, Apr. 1999.

[138] Nunna K, Srinivasan D. An Agent based Energy Market Model for Microgrids with Distributed Energy Storage Systems. IEEE Int Conf Power Electron Drives Energy Syst PEDES 2016 2017;2016-January:1-5. doi:10.1109/PEDES.2016.7914491.

[139] Reis IFG, Lopes MAR, Antunes CH. Energy transactions between energy community members: An agentbased modeling approach. 2018 Int. Conf. Smart Energy Syst. Technol. SEST 2018 - Proc., 2018. doi:10.1109/SEST.2018.8495635.

[140] Sesetti A, Kumar Nunna HSVS, Doolla S, Rathore AK. Multi-agent based energy trading platform for energy storage systems in distribution systems with inter-connected microgrids. 2018 IEEE Ind Appl Soc Annu Meet IAS 2018 2018:1-8. doi:10.1109/IAS.2018.8544691.

[141] Luo F, Chen Y, Xu Z, Liang G, Zheng Y, Qiu J. Multiagent-Based Cooperative Control Framework for Microgrids' Energy Imbalance. IEEE Trans Ind Informatics 2017;13:1046-56. doi:10.1109/TII.2016.2591918.

[142] Luo F, Dong ZY, Liang G, Murata J, Xu Z. A Distributed Electricity Trading System in Active Distribution Networks Based on Multi-Agent Coalition and Blockchain. IEEE Trans Power Syst early access. doi:10.1109/TPWRS.2018.2876612.

[143] Gazafroudi AS, Prieto J, Corchado JM. Virtual organization structure for agent-based local electricity trading. Energies 2019;12:1-11. doi:10.3390/en12081521. 
$52 \quad$ Submitted to Elsevier Science

[144] Ma J, Liu Y, Song L, Han Z. Multiact Dynamic Game Strategy for Jamming Attack in Electricity Market. IEEE Trans Smart Grid 2015;6:2273-82. doi:10.1109/TSG.2015.2400215.

[145] Moiseeva E, Hesamzadeh MR, Biggar DR. Exercise of Market Power on Ramp Rate in Wind-Integrated Power Systems. IEEE Trans Power Syst 2015;30:1614-23. doi:10.1109/TPWRS.2014.2356255.

[146] Wang G, Zhang Q, Li H, McLellan BC, Chen S, Li Y, et al. Study on the promotion impact of demand response on distributed PV penetration by using non-cooperative game theoretical analysis. Appl Energy 2017;185:1869-78. doi:10.1016/j.apenergy.2016.01.016.

[147] Shafie-Khah M, Catalão JPS. A stochastic multi-layer agent-based model to study electricity market participants behavior. IEEE Trans Power Syst 2015;30:867-81. doi:10.1109/TPWRS.2014.2335992.

[148] Dehghanpour K, Hashem Nehrir M, Sheppard JW, Kelly NC. Agent-Based Modeling of Retail Electrical Energy Markets with Demand Response. IEEE Trans Smart Grid 2018;9:3465-75. doi:10.1109/TSG.2016.2631453.

[149] Rassaei F, Soh WS, Chua KC. Distributed Scalable Autonomous Market-Based Demand Response via Residential Plug-In Electric Vehicles in Smart Grids. IEEE Trans Smart Grid 2018;9:3281-90. doi:10.1109/TSG.2016.2629515.

[150] Pourbabak H, Luo J, Chen T, Su W. A novel consensus-based distributed algorithm for economic dispatch based on local estimation of power mismatch. IEEE Trans Smart Grid 2018;9:5930-42. doi:10.1109/TSG.2017.2699084.

[151] Long C, Wu J, Zhang C, Cheng M, Al-Wakeel A. Feasibility of Peer-to-Peer Energy Trading in Low Voltage Electrical Distribution Networks. Energy Procedia 2017;105:2227-32. doi:10.1016/j.egypro.2017.03.632.

[152] Liu, T., Tan, X., Sun, B., Wu, Y., Guan, X., \& Tsang, D. H. K. (2016). Energy management of cooperative microgrids with P2P energy sharing in distribution networks. 2015 IEEE International Conference on Smart Grid Communications, $\quad$ SmartGridComm $\quad$ 410-415. https://doi.org/10.1109/SmartGridComm.2015.7436335.

[153] Liu, Z., Wu, Q., Member, S., Huang, S., \& Member, S. (2018). Optimal Day-Ahead Charging Scheduling of Electric Vehicles Through an Aggregative Game Model. IEEE Transactions on Smart Grid, 9(5), 51735184. https://doi.org/10.1109/TSG.2017.2682340. 
[154] Suganya S, Raja SC, Venkatesh P. Simultaneous coordination of distinct plug-in Hybrid Electric Vehicle charging stations: A modified Particle Swarm Optimization approach. Energy 2017;138:92-102. doi:10.1016/j.energy.2017.07.036.

[155] Wu X, Che A. A memetic differential evolution algorithm for energy-efficient parallel machine scheduling. Omega (United Kingdom) 2019;82:155-65. doi:10.1016/j.omega.2018.01.001.

[156] Qian LP, Wu Y, Zhang YJA, Huang J. Demand response management via real-time electricity price control in smart grids. IEEE Journal on Selected areas in Communications, 2013, 31(7): 1268-1280.

[157] Lin WM, Tu CS, Tsai MT. Energy management strategy for microgrids by using enhanced bee colony optimization. Energies 2016;9:1-16. doi:10.3390/en9010005.

[158] Derakhshan G, Shayanfar HA, Kazemi A. The optimization of demand response programs in smart grids. Energy Policy 2016;94:295-306. doi:10.1016/j.enpol.2016.04.009.

[159] Rahmaniani R, Crainic TG, Gendreau M, Rei W. The Benders decomposition algorithm: A literature review. Eur J Oper Res 2017;259:801-17. doi:10.1016/j.ejor.2016.12.005.

[160] Zheming L, Guo Y. Robust optimization based bidding strategy for virtual power plants in electricity markets. IEEE Power Energy Soc Gen Meet 2016;2016-November:1-5. doi:10.1109/PESGM.2016.7742043.

[161] Ghasemi A, Mortazavi SS, Mashhour E. Hourly demand response and battery energy storage for imbalance reduction of smart distribution company embedded with electric vehicles and wind farms. Renew Energy 2016;85:124-36. doi:10.1016/j.renene.2015.06.018.

[162] Monfared HJ, Ghasemi A. Retail electricity pricing based on the value of electricity for consumers. Sustain Energy, Grids Networks 2019;18:100205. doi:10.1016/j.segan.2019.100205.

[163] Samadi P, Mohsenian-Rad A-H, Schober R, Wong VWS, Jatskevich J. Optimal Real-Time Pricing Algorithm Based on Utility Maximization for Smart Grid. 2010 First IEEE Int Conf Smart Grid Commun 2010:415-20. doi:10.1109/smartgrid.2010.5622077.

[164] Deng R, Yang Z, Hou F, Chow MY, Chen J. Distributed Real-Time Demand Response in MultisellerMultibuyer Smart Distribution Grid. IEEE Trans Power Syst 2015;30:2364-74. doi:10.1109/TPWRS.2014.2359457.

[165] Carlos J, Student B, Liu C. Bilateral Electricity Market in a Distribution System Environment. IEEE Trans Smart Grid 2019;PP:1. doi:10.1109/TSG.2019.2910216. 
[166] Namerikawa T, Okubo N, Sato R, Okawa Y, Ono M. Real-Time Pricing Mechanism for Electricity Market with Built-In Incentive for Participation. IEEE Trans Smart Grid 2015;6:2714-24. doi:10.1109/TSG.2015.2447154.

[167] Wang Y, Wang S, Wu L. Distributed optimization approaches for emerging power systems operation: A review. Electr Power Syst Res 2017;144:127-35. doi:10.1016/j.epsr.2016.11.025.

[168] Doostizadeh M, Aminifar F, Lesani H, Ghasemi H. Multi-area market clearing in wind-integrated interconnected power systems: A fast parallel decentralized method. Energy Convers Manag 2016;113:13142. doi:10.1016/j.enconman.2016.01.047.

[169] Loukarakis E, Bialek JW, Dent CJ. Investigation of Maximum Possible OPF Problem Decomposition Degree for Decentralized Energy Markets. IEEE Trans Power Syst 2015;30:2566-78. doi:10.1109/TPWRS.2014.2365959.

[170] Nguyen DH, Azuma S ichi, Sugie T. Novel Control Approaches for Demand Response with Real-time Pricing using Parallel and Distributed Consensus-based ADMM. IEEE Trans Ind Electron 2018;66:7935-45. doi:10.1109/TIE.2018.2881938.

[171] Moret F, Baroche T, Sorin E, Pinson P. Negotiation algorithms for peer-to-peer electricity markets: Computational properties. 20th Power Syst Comput Conf PSCC 2018 2018:1-7. doi:10.23919/PSCC.2018.8442914.

[172] Rastegar H, Hosseinian SH, Vahidi B, Khazaei H. Two-level decision-making model for a distribution company in day-ahead market. IET Gener Transm Distrib 2015;9:1308-15. doi:10.1049/iet-gtd.2014.0797.

[173] Soares I, Alves MJ, Antunes CH. Designing time-of-use tariffs in electricity retail markets using a bi-level model - Estimating bounds when the lower level problem cannot be exactly solved. Omega (United Kingdom) 2019. doi:10.1016/j.omega.2019.01.005.

[174] Ottesen SØ, Tomasgard A, Fleten SE. Multi market bidding strategies for demand side flexibility aggregators in electricity markets. Energy 2018;149:120-34. doi:10.1016/j.energy.2018.01.187.

[175] Li J, Liu F, Li Z, Shao C, Liu X. Grid-side flexibility of power systems in integrating large-scale renewable generations: A critical review on concepts, formulations and solution approaches. Renew Sustain Energy Rev 2018;93:272-84. doi:10.1016/j.rser.2018.04.109.

[176] Dupačová J, Gröwe-Kuska N, Römisch W. Scenario reduction in stochastic programming. Mathematical 
programming 2003;95(3): 493-511. doi: 10.1007/s10107-002-0331-0.

[177] Carrión M, Arroyo JM, Conejo AJ. A bilevel stochastic programming approach for retailer futures market trading. IEEE Trans Power Syst 2009;24:1446-56. doi:10.1109/TPWRS.2009.2019777.

[178] Liu N, Yu X, Wang C, Li C, Ma L, Lei J. Energy-sharing model with price-based demand response for microgrids of peer-to-peer prosumers. IEEE Transactions on Power Systems, 2017, 32(5): 3569-3583. doi: 10.1109/TPWRS.2017.2649558.

[179] Zachar M, Daoutidis P. Microgrid/Macrogrid Energy Exchange: A Novel Market Structure and Stochastic Scheduling. IEEE Trans Smart Grid 2017;8:178-89. doi:10.1109/TSG.2016.2600487.

[180] Liu Z, Wu Q, Oren SS, Huang S, Li R, Cheng L. Distribution locational marginal pricing for optimal electric vehicle charging through chance constrained mixed-integer programming. IEEE Trans Smart Grid 2018;9:644-54. doi:10.1109/TSG.2016.2559579.

[181] Zhou Y, Wei Z, Sun G, Cheung KW, Zang H, Chen S. A robust optimization approach for integrated community energy system in energy and ancillary service markets. Energy 2018;148:1-15. doi:10.1016/j.energy.2018.01.078.

[182] Liu G, Xu Y, Tomsovic K. Bidding strategy for microgrid in day-ahead market based on hybrid stochastic/robust optimization. IEEE Trans Smart Grid 2016;7:227-37. doi:10.1109/TSG.2015.2476669.

[183] Liu Y, Li Y, Gooi HB, Jian Y, Xin H, Jiang X, et al. Distributed Robust Energy Management of a Multimicrogrid System in the Real-Time Energy Market. IEEE Trans Sustain Energy 2019;10:396-406. doi:10.1109/TSTE.2017.2779827. 